\title{
Development of Dynamic Centrifuge Models of Underground Structures near Tall Buildings
}

\author{
S. Dashti ${ }^{1}$, Y. M.A. Hashash², K. Gillis ${ }^{3}$, M. Musgrove ${ }^{4}$, M. Walker ${ }^{5}$
}

ABSTRACT: A series of six centrifuge experiments was designed and conducted to assess the seismic influence of a mid to highrise building on adjacent shallow underground structures. The buildings modeled in this study (12 and 42 stories) were the tallest structures tested in centrifuge to date. In designing these experiments, it was important to represent the modal frequencies, base shear, base moment, and yield characteristics of realistic mid and highrise structures, in order to transmit realistic seismic demands onto the underground structures. For the midrise structure, it was possible to simulate the height, mass, and three primary modes of response with a simplified, scaled model in centrifuge. For the highrise structure, additional simplifications were necessary due to a limited overhead space. A scaled, single-degree-of-freedom structure could capture the fundamental frequency, mass, and therefore base shear of a representative 42-story highrise building, while other properties were sacrificed. The six experiments with varied payloads required similar base motions to experimentally evaluate the seismic impact of buildings on underground structures. The heavy structures applied an unprecedented demand on the shaking table under increased gravity, which was expected to adversely affect the repeatability of motions. Even though the achieved base motions were significantly de-amplified compared to those desired, their coefficient of variation among six experiments was less than 0.2 in the frequency range of interest $(0.2$ to $5 \mathrm{~Hz})$, indicating acceptable repeatability. The buildings were instrumented during the centrifuge tests to measure their base shear and roof drifts. The results were consistent with pushover analyses and design requirements, indicating realistic overall stiffness, yielding characteristics, and shear forces transmitted to the foundation. The overall response of the system indicates that, with reasonable approximations, the seismic forces transferred from tall buildings to the foundation soil and an adjacent underground structure can be successfully modeled and evaluated in centrifuge.

\footnotetext{
${ }^{1}$ Assistant Professor, University of Colorado Boulder, CO, USA, email: shideh.dashti@colorado.edu

${ }^{2}$ Professor, University of Illinois at Urbana-Champaign, IL, USA, email: hashash@illinois.edu

${ }^{3}$ Ph.D. Student, University of Colorado Boulder, CO, USA, email: kenneth.gillis@colorado.edu

${ }^{4}$ Ph.D. Student, University of Illinois at Urbana-Champaign, IL, USA, email: mmusgro2@illinois.edu

${ }^{5}$ Senior Geotechnical Engineer, ARUP, San Francisco, CA, USA, email: martin.walker@arup.com
}

(C) 2016. This manuscript version is made available under the Elsevier user license http://www.elsevier.com/open-access/userlicense/1.0/ 


\section{INTRODUCTION}

In dense urban environments, underground infrastructure is often built in close proximity to tall buildings. Understanding the seismic interactions among complex underground structures, soil, and adjacent buildings is a key step toward the design of resilient cities. Centrifuge modeling is an effective tool to study the mechanics of these interactions in order to validate advanced numerical models that are used in design. In a centrifuge, scaled models of soil and multiple structures may be studied under realistic confining pressures and earthquake loads in a cost-effective manner. The increasingly complex nature of structures and loading conditions that need to be studied, however, requires an understanding of the approximations necessary in modeling the main components of urban infrastructure in centrifuge and in evaluating their interaction.

The seismic response of underground structures is controlled by the deformation and inertial response of the surrounding soil because, unlike aboveground structures, they are enclosed in soil and do not experience free vibration (Hashash et al. 2001; 2010). In dense urban environments, these underground structures are often built in close vicinity of existing or new tall buildings. Previous studies have shown the important influence of the soil, foundation, and superstructure interaction (SFSI) on the deformation and inertial response of the underlying soil, particularly at shallow depths (e.g., Stewart et al. 1999; Pecker and Pender 2000; Martin and Lam 2000; Pitilakis et al. 2004; Dashti et al. 2010). Mason et al. (2013) and Trombetta et al. (2013) also showed experimentally that an isolated footing of a 3-story, lowrise building adjacent to (or restrained by) a deeply embedded, 9-story, midrise structure experiences smaller seismic settlements compared to a footing with no adjacent structure. However, the asymmetrical response of the restrained lowrise building was shown to apply additional demands (e.g., column moments) on the supported superstructure compared to a free, isolated scenario. Ignoring the influence of neighboring structures in design was shown as potentially detrimental. Hence, the hypothesis tested in this study is that the response of shallow, underground structures is strongly influenced by the forces transmitted from an adjacent superstructure to the foundation soil, and that larger forces are transmitted by heavier structures. 
The influence of an adjacent tall building on the seismic demand imposed on shallow, underground box structures during earthquake motions has not been investigated experimentally in the past. This has hindered the development of well-calibrated and validated procedures that take into account soilstructure-underground structure-interaction (SSUSI) in the seismic design of underground facilities in dense urban areas.

In this paper, we discuss the design, construction, and approximations necessary for centrifuge modeling of seismic interactions between tall buildings and adjacent underground box structures. This work is part of a larger research study that employs a combined experimental-numerical approach to evaluate seismic SSUSI. The seismic performance of underground structures and their interaction with tall buildings as observed experimentally and numerically will be discussed in other papers.

\section{TESTING PLAN}

Figure 1 shows a schematic drawing of the centrifuge testing plan performed at the University of California, Davis Center for Geotechnical Modeling (UCD-CGM). A relatively simple soil profile (uniform, medium-dense, dry Nevada sand) was selected to minimize changes in soil relative density after subsequent shakes and avoid complications associated with water flow for this first of its kind study. Experiments T-No Bldg and E-No Bldg were designed to evaluate the individual response of a model tunnel and braced excavation in dry, medium-dense sand subject to a series of earthquake motions. These tests served as the baseline experiments with no adjacent building present. In the subsequent tests ( $\mathrm{T}$ Midrise, E-Midrise, T-Highrise, and E-Highrise), the tunnel and braced excavation were each separately placed near a model representing a midrise or highrise building. The design of the experiments and the structures included the following considerations:

1. Box tunnel structure: it was important to simulate the lateral stiffness and racking deformations expected for realistic transportation tunnels. Also, a tunnel structure was desired that had small, yet realistic, dimensions to increase the separation between structures and container boundaries and reduce boundary effects. 
2. Temporary braced excavation: the models needed to reflect a realistic lateral stiffness, while ensuring stability under static and seismic loading with and without an adjacent highrise building. Further, given the density of instrumentation used inside the braced excavation, the spacing of struts needed to be practical in the scaled centrifuge model.

3. Buildings: The models needed to generate seismic forces and moments similar to those that midrise and highrise buildings transmit to the soil and an adjacent underground structure. Hence, it was important to simulate their modal frequencies, modal shapes, base shear, base moment, and yield characteristics. Designing a scaled highrise structure with realistic dimensions and dynamic properties that complied with the seismic design requirements was a challenge, given the overhead space limitations of the centrifuge container.

The following sections summarize the design of model underground and aboveground structures to achieve these objectives and areas where approximations were needed.

\section{MODELING OF SHALLOW UNDERGROUND STRUCTURES}

\section{Permanent Box Tunnel Structure}

A 14 x 8 x 0.8 m (width $\times$ height $x$ thickness, W x H x TH) reinforced concrete box tunnel structure was selected and modeled in centrifuge with a corresponding 21.5 x 12.3 x $0.88 \mathrm{~cm}$ (W x H x TH) aluminum box structure under $65 \mathrm{~g}$ of centrifugal acceleration (see Table 1).

Six tunnel configurations representative of transportation tunnels were considered, as shown in Figure 2. The stiffness and peak racking displacement of each option were then evaluated relative to the estimated free-field racking displacement under different motions, in order to select the smallest box structure option that experienced racking displacements 1 to 1.5 times greater than those expected in the free-field soil to simulate the lateral stiffness and racking deformations expected for realistic transportation tunnels. Racking is a critical measure of seismic performance for an underground box structure. Hence, its proper characterization was important.

Free-field racking displacements $\left(\Delta_{\mathrm{FF}}\right)$ corresponding to the elevation of each box structure option were obtained during each ground motion from 1-D equivalent-linear and nonlinear analyses, 3-D 
nonlinear shear-beam analyses, and prior centrifuge measurements. The 1-D analyses were multi-degreeof-freedom (MDOF), lumped mass models conducted in DEEPSOIL (Hashash et al. 2015b) using equivalent-linear and nonlinear soil models. The 3-D shear-beam analyses were finite element models conducted in OpenSees using the nonlinear, Pressure-Dependent-Multi-Yield (PDMY) soil model (Elgamal 2002; Yang 2000), as detailed by Hashash et al. (2015a). Accelerometer recordings during a preliminary free-field centrifuge test (without any model structures) at University of Colorado Boulder (CUB) were also used to experimentally evaluate the selected site response tools in the estimation of freefield behavior. Figure 2 presents the maximum free-field racking displacements obtained from the described methods for each motion and structure height option.

The racking displacement of the box tunnel structures ( $\left.\Delta_{\text {structure }}\right)$ was estimated during design based on the NCHRP 611 guideline. In this procedure, the flexibility ratio $(F)$ was calculated as $F=\left(G_{m} \cdot B\right) /\left(K_{s} \cdot H\right)$, where $G_{m}$ is the strain-compatible shear modulus of soil in the free-field, $B$ is the width of the box structure, $K_{s}$ is the racking stiffness of the structure, and $H$ is the structure height. To estimate $\mathrm{G}_{\mathrm{m}}$, the equivalent shear strain $\left(\gamma_{\mathrm{eq}}=0.65 \gamma_{\max }\right)$ was needed, where the maximum shear strain, $\gamma_{\max }$, was obtained by dividing the peak free-field racking displacement obtained from different procedures by the height of the corresponding structure option. The small-strain, maximum soil shear modulus $\left(\mathrm{G}_{\max }\right)$ was then estimated at the depth corresponding to the mid-height of each underground structure option using the average of empirical relations proposed by Seed and Idriss (1970), Bardet (1993), Jamiolkowski et al. (1991), Menq (2003), and Hardin and Drnevich (1972). The median modulus reduction $\left(\mathrm{G}_{\mathrm{m}} / \mathrm{G}_{\max }\right.$ versus $\gamma$ ) curve proposed by Darendeli (2001) at that depth was adopted and corrected for the implied shear strength of soil, as detailed by Hashash et al. (2015a). The soil $\gamma_{\mathrm{eq}}$ was used together with $\mathrm{G}_{\max }$ to obtain $\mathrm{G}_{\mathrm{m}}$ from the strength-corrected modulus reduction curve for each structure option and ground motion. The values of $G_{\max }$ and $G_{m}$ in the soil specimen need to be measured during the centrifuge experiments and the uncertainty in their estimation quantified prior to numerical simulations of a given test. This can be accomplished using bender elements to obtain $\mathrm{G}_{\max }$ and an array of accelerometer recordings in the far- 
field during earthquake loading to obtain $\mathrm{G}_{\mathrm{m}}$. In engineering practice the uncertainty in these values needs to be considered during design.

The racking stiffness $\left(\mathrm{K}_{\mathrm{s}}\right)$ of each box structure option was estimated through 2-D frame analyses with a known horizontal load applied to the roof of the frame, keeping the base nodes fixed from translation but not rotation (i.e., a pin connection). The ratio of roof lateral load to displacement was subsequently used to obtain the $K_{s}$ of each structure option. The Flexibility Ratio $(F)$ could then be calculated. Using the $F$ and the maximum free-field racking displacement $\left(\max \mid \Delta_{\mathrm{FF}}\right)$ as shown in Figure 2, the racking ratio $\left(R=\left(\max \mid \Delta_{\text {structure }}\right) /\left(\max \left|\Delta_{\mathrm{FF}}\right|\right)\right)$ could be estimated as $R=2 \mathrm{~F} /(1+F)(\mathrm{NCHRP} 611)$. The $\max \mid \Delta$ Structure could then be obtained for each combination of structure option and ground motion. Box structure Option 4 was selected for use in the centrifuge, providing racking ratios between 0.9 and 1.6, while still maintaining realistic dimensions.

The target box structure was designed in prototype scale based on the material properties of reinforced concrete. In centrifuge testing, aluminum is often used to fabricate scale models instead of reinforced concrete because of its similar unit weight and easier fabrication. An equivalent section thickness of aluminum was calculated to maintain the racking stiffness $\left(\mathrm{K}_{\mathrm{s}}\right)$ of the target box structure in the scale model. Table 1 summarizes the properties of the box structure as originally designed and as modified for centrifuge testing in prototype scale. The dimensions of the equivalent aluminum structure were converted to model scale units (at $65 \mathrm{~g}$ ) for fabrication. The simplified permanent box structure model was constructed using four aluminum plates, each with a wall thickness of $0.88 \mathrm{~cm}$. The roof and floor sections were welded to the inside upper and lower corners of the wall plates to provide fixed connections.

\section{Temporary Excavation}

A 14 x 12 m (width x depth, W x D) excavation supported with steel solider piles and three levels of steel tube struts horizontally spaced at $4.2 \mathrm{~m}$ was selected and modeled in centrifuge with aluminum walls and tube struts that provided an equivalent lateral stiffness (see Table 2). 
Temporary excavations in seismic regions are often designed for a lower level earthquake scenario. However, the suite of acceleration time histories used to design the permanent box structure were also used in the design and centrifuge testing of the target excavation. This was done to allow for meaningful comparisons between the tests by removing a potential source of variability in the response.

The target prototype braced excavation was designed based on the properties of steel soldier piles and steel tube struts (as summarized in Table 2). Equivalent aluminum wall sections and tube struts were selected for the simplified centrifuge excavation model to provide a similar equivalent racking stiffness $\left(\mathrm{K}_{\mathrm{s}}\right)$ as the target, while ensuring their model scale dimensions were readily available. The selected horizontal strut spacing was also influenced by the need to accommodate numerous instruments and the associated wiring. Table 2 summarizes the properties of the simplified braced excavation used in the centrifuge tests.

At the design stage, the presence of an adjacent building was simulated in Plaxis-2D only as an added overburden pressure of $658 \mathrm{kPa}$ on a massless plate (roughly corresponding to a 50-story building). Plaxis-2D was used in designing the temporary excavation, as it is commonly used in engineering practice for the analysis of excavations. The inertial response of the building and its influence on the forces applied to the excavation were not modeled during the design, primarily because building properties had not yet been determined. However, the influence of the building weight alone on the static and dynamic vertical and lateral stresses imposed on the soil and excavation during different motions was considered sufficient to ensure model stability. Figure 3 shows the maximum relative lateral deflection of the target excavation walls estimated during the KobeTAK motion with and without the presence of an adjacent building. The maximum absolute bending moments and shear forces along the walls and the maximum axial forces on the struts were checked against their corresponding design strength values (AISC 2006), to ensure stability during all motions. As shown in Figure 4, the strength values were only exceeded on the bottom strut under dynamic loading. Since at the time the excavation was designed, the first experiment (T-No Bldg) was completed and the achieved motions were known to be significantly lower than those 
used in design, the exceedance of strut design strength was judged to be acceptable for the purpose of these tests.

Fabrication of the temporary excavation was more challenging than the permanent box structure due to additional components that needed to be held together during model preparation and the amount of instrumentation within the limited space. The design specified 36 length-adjustable struts to be used in the model. Additionally, a pin connection was required between the excavation walls and struts (see Figure 15b), as the struts were intended to serve only as axial elements. Each strut was constructed using a hollow aluminum tube with an insert at both ends that could be used to adjust the length. Each insert was constructed using a thread, a steel acorn nut, and two lock nuts. The acorn nut connected the strut to the excavation wall. The excavation walls were machined with small round indentations at the location of the struts, to provide a ball (strut) and socket (indentation) type connection that would allow for rotation. The walls were held in place and soil pluviated around it. Then, each strut was placed into position and its length was adjusted. The lock nuts were then tightened to prevent the strut length from changing during the test. This preparation method did not mimic the typical construction process in the field. Despite the simplifications in the properties of soil and structures as well as construction method, the centrifuge test results under controlled conditions were still expected to provide valuable insights into SSUSI and enable validation of numerical tools, which can later evaluate more realistic conditions.

\section{MODELING OF TALL BUILDINGS}

\section{Midrise Building}

A 13 story Steel Moment Resisting Frame (SMRF) structure with footprint dimensions of 38.5 x 22.5 $\mathrm{m}$, height of $50 \mathrm{~m}$ aboveground, and a 1-story basement was selected and modeled in centrifuge with a simplified, scaled, 3-DOF steel structure that captured the midrise building's three primary modes, yield characteristics, contact pressure, base shear, and base moment. At the time the midrise building was designed, the first two baseline experiments, T-No Bldg and E-No Bldg, were completed. Therefore, the achieved base motions and soil surface accelerometer recordings were available for use in the design of the buildings. Although these surface accelerations recorded halfway between the underground structure 
wall and container boundaries in T-No Bldg and E-No Bldg were intended to approximate free-field conditions, they were likely affected by the presence of underground structures and are therefore referred to as far-field in this paper, rather than free-field.

A range of typical buildings in Los Angeles (LA) and San Francisco (SF), California were evaluated. Steel and reinforced concrete moment resisting frame (SMRF and RCMF), 13 to 15-story structures with 1 to 2-story basements were found common in LA and SF with total seismic weights ranging from about 39,000 to 135,000 kN (as summarized in Table 3). Figure 5a shows the seismic shear demand imposed on SMRF buildings placed either in LA or SF based on ASCE 7-10. The ASCE 7-10 shear demands on these buildings were then compared with those induced by the ground motions measured in T-No Bldg at the container base and far-field soil surface. The shear demands obtained from ASCE 7-10 for a building in LA controlled the design of a midrise SMRF building, as shown in Figure 5a.

A 13-story, SMRF building was selected as the target midrise building for this study with properties summarized in Table 3. This model represented the largest and heaviest structure tested in a centrifuge in advance of the later highrise building model. The tallest structure modeled in centrifuge prior to these experiment was a 9-story building by Mason et al. (2013). The midrise building was simplified from 13DOFs to a 3-DOF system, in order to ensure the centrifuge model captured the three primary modes of vibration that dominate its inertial interaction and reduce the number of structural masses to a practical and manageable number in a scaled model with dense instrumentation. The seismic shear load demand per floor was subsequently estimated for the selected structure based on ASCE 7-10 in LA, as shown in Figure 5b. Detailed properties and dimensions of the simplified centrifuge midrise building are summarized in Table 3 in both prototype and model scales.

Beam and column fuses are areas with a reduced cross section, which are often used by structural engineers to control and isolate the location of structural nonlinearity and yield. For the midrise structure, fuses were strategically designed at the beam and column ends to control the inelastic deformations of the frame, similar to the approach presented by Trombetta et al. (2013) and Chen et al. (2013). Pushover and modal analyses were performed in OpenSees v.2.4.3 (Mazzoni et al. 2006) to design the structural 
elements and fuses, while satisfying the seismic code requirements. OpenSees was employed as a generalpurpose finite element platform for modeling structural response and soil-structure interaction. The properties of the fuses were varied in OpenSees, producing different natural periods as well as stiffness and yield characteristics, as shown for the three models considered in Figure 6. Model II was selected with first three modal periods of 3.02, 0.85 , and $0.43 \mathrm{~s}$ in prototype scale, as it complied with ASCE 7-10 design requirements in terms of allowable base shear and drift, and it provided a fundamental period similar to the target structure. The type of fuses selected on the beam and column ends of the centrifuge midrise building are shown in Figure 7 in model scale. The moment-rotation behavior of the fuses was later measured in flight during the centrifuge experiments using strain gauges.

\section{Highrise Building}

A 42-story SMRF structure with a concrete core, footprint dimensions of 33 x $33 \mathrm{~m}$, height of $142 \mathrm{~m}$, and a 4-story basement was selected and modeled in the centrifuge with a simplified, scaled, SDOF, SMRF structure that captured the highrise building's fundamental mode, yield characteristics, contact pressure, and base shear, but not its height, base moment, nor higher modes of response.

The challenge in designing the highrise building was to design a structure that had realistic dimensions and dynamic properties, complied with the seismic design requirements in California, and also satisfied the overhead space limitations of the centrifuge container. No centrifuge experiments had been performed on a highrise model structure prior to T-Highrise and E-Highrise by other researchers.

The Tall Building Initiative (TBI) Task 12 Final Report (Moehle et al. 2011) presented the results of dynamic time history analyses on selected tall buildings in San Francisco, CA. Figure 8 and Figure 9 summarize the range of fundamental periods, seismic shear demands, and overturning moment demands in the two horizontal directions for the tall building options considered in the TBI report (building models 1A through 3C). Concrete core SMRF building models $2 \mathrm{~B}$ and $2 \mathrm{C}$ in this report were selected as the target highrise buildings for this study. The target buildings had 42 stories aboveground and 4 stories of basement. Their other relevant properties are summarized in Table 3. Figure 10 compares the maximum credible earthquake (MCE) target response spectrum used in the TBI report to the response spectra of the 
motions recorded at the far-field soil surface in each of the two baseline experiments (T-No Bldg and ENo Bldg). At the fundamental period of the target highrise building (approximately $4 \mathrm{~s}$ ), the largest expected horizontal base shear demand in centrifuge (i.e., $22,000 \mathrm{kN}$ ) was approximately $46 \%$ of the TBI demand (47,000 kN), as shown in in Figure 10.

As in the midrise structure design, static pushover analyses were performed in OpenSees and SAP2000 to design a simplified structure that simulated the dynamic properties of a realistic highrise building. SAP2000 is commonly used in structural design, the results of which were compared with finite element simulations in OpenSees. The target building footprint dimensions of 69 x 69 m were too large to fit within the centrifuge container at the selected level of centrifugal acceleration (65g). Therefore, footprint dimensions of $33 \times 33 \mathrm{~m}$, which represented the footprint of the reinforced concrete core of the target highrise structure, were selected instead. The overhead height restrictions of the centrifuge dictated that simulation of the center of gravity of the target building was not possible. This limitation precluded the simulation of higher modes, seismic moments, and the resulting rocking tendencies of the building. The total seismic weight and fundamental period, however, could be simulated, and were expected to strongly influence SSUSI and the response of an adjacent underground structure.

A simplified single-degree-of-freedom (SDOF) system was designed to simulate the fundamental period, weight, and shear capacity of the target highrise building. Figure 11a presents the first series of pushover analyses conducted in OpenSees to select the properties of a simplified SDOF structure. Model IV had a fundamental period near the target value of $4 \mathrm{~s}$, while simultaneously satisfying the shear capacity requirements in TBI. Figure $11 \mathrm{~b}$ compares the static pushover analyses performed on the final design (Option IV) using OpenSees and SAP2000. The horizontal base shear causing initial yielding of the structure was estimated at $61,000 \mathrm{kN}$, while the largest expected horizontal base shear demand in centrifuge was 22,000 kN. Therefore, this structure was expected to respond within its linear elastic range in the centrifuge for the series of achieved ground motions in previous tests. As a result, fuses were omitted from the beams and columns to simplify the design and fabrication. Two motions (Los Gatos, discussed in more detail later in the paper) were added to the highrise test, because they had more content 
at higher periods (4 to $5 \mathrm{~s}$ ), in order to amplify the base shear and induce stresses in the model highrise structure closer to its yield stress. However, these ground motions were applied after the baseline ground motions used in previous tests to maintain experimental comparison.

Static structural analyses were performed in AISC 360-05 and SAP2000 to ensure adequate static factors of safety of beams and columns against axial, shear, and bending yield under $65 \mathrm{~g}$ of centrifugal acceleration. The final design was verified by changing the geometric transformation of the elements in OpenSees, as shown in Figure 11c. The P-delta effect was also implemented in the final design, showing no significant change in the behavior of the structure for the expected range of roof displacements. Table 3 presents the final properties of the simplified SDOF centrifuge model of the target highrise building in both prototype and model scale.

The simplified highrise building model was the heaviest single structure ever tested in a centrifuge. As a result, the design of the columns, beams, and the top mass as well as the selection of base motions to excite this building went through several iterations by the research team and centrifuge staff. One challenge during fabrication was a practical strategy for placing $150 \mathrm{~kg}$ (at $1 \mathrm{~g}$ ) of mass to the top story without altering the frame's intended stiffness and deformation pattern. The original design of the top floor mass included large steel plates at the top and bottom of the cross beams. That design would limit rotation of the top floor and add unwanted stiffness to the building. In the final design, eight smaller steel plates were placed at the top and bottom of each individual cross beam, as shown in Figure 12b.

All fasteners on the structure were of the highest grade to minimize the possibility of bolt or nut failure. Loading the highrise superstructure onto the centrifuge model was done using an overhead crane positioned above the centrifuge bucket. The highrise superstructure was installed on the model after it had been loaded onto the centrifuge shake table to prevent damage to the model during transportation. Safety straps were attached to each corner of the building top floor to catch or restrain the structure if tipping or component failure occurred during testing. 


\section{Basement Walls}

The basement of both midrise and highrise buildings was designed as a box with an open bottom and filled with the test soil. The building was connected to the basement through a diaphragm or base plate at the ground level (as shown in Figure 12), which transferred the weight and shear loads from the building to the perimeter basement walls, and then to the soil and adjacent underground structure. The design approach for the basement, therefore, deviated from other components of the soil-structure-underground structure system presented, in that it was not intended to represent realistic prototype conditions. This was a necessary simplification given the limitations within the centrifuge. The basement was modeled full of soil, because the inclusion of an empty basement would significantly reduce the confining pressure under the building. The reduced confining pressure would reduce the influence of the building on the seismic performance of the adjacent box structure and their interactions, which was counter to the goal of this study.

The response of the soil-basement-superstructure system was evaluated for both buildings under two conditions for stability: 1) sliding and overturning about the building base plate; 2) sliding and overturning about the bottom of the basement walls. The basement wall section thickness and height were designed for each building model to reach a minimum factor of safety of 2 in either condition to ensure static and seismic stability of the entire system. The properties of the basement are summarized in Table 3 in prototype and model scale.

\section{EXPERIMENTAL SETUP AND INSTRUMENTATION}

\section{Centrifuge Container and Soil Medium}

An ideal container for dynamic centrifuge experiments is one that: 1) maintains a horizontal cross section, 2) has a negligible mass, 3) provides no additional lateral stiffness to the soil deposit, and 4) applies the same dynamic shear stresses on the soil-container interface as those on the horizontal plane (Whitman and Lambe 1986). Further, when modeling the dynamic response of complex soil-structure systems (as in this study), it is advantageous to use a container that has simple and continuous boundaries. The large flexible-shear-beam (FSB) container (Divis et al. 1996) made of aluminum and rubber frames 
with side shear rods was selected in this study because of its lower lateral stiffness (reducing boundary effects) and also its simple and continuous boundaries.

The centrifugal acceleration level and soil height needed to be determined to maximize the prototype size of the structures that could fit within the available container with a limited size and overhead space. However, it was simultaneously preferred to limit the total weight applied on the shaking table, the increase of which would affect its performance and repeatability of motions. Based on the available container size, a centrifugal acceleration of $65 \mathrm{~g}$ was selected to provide the desired prototype dimensions. The large size of the FSB model container (inside dimensions: $107 \mathrm{~L} \mathrm{x} 51 \mathrm{~W}$ x $38 \mathrm{H}$ m in prototype scale at 65g) allows for the simulation of a 38 m-thick soil deposit. But soil was only pluviated to simulate the response of a 26 m-thick deposit in prototype scale, in order to reduce the total weight of the model and simultaneously increase the available height above the surface of the soil for the tall buildings.

The asymmetry of the model during the midrise and highrise experiments was expected to increase rocking tendencies of the entire container. Therefore, a weight was placed at the base of the container to balance the moment induced by the presence of the corresponding building. Dry, uniform, medium-dense Nevada Sand $\left(D_{50}=0.14 \mathrm{~mm}, C_{\mathrm{u}}=2.07, e_{\min }=0.53, e_{\max }=0.9, \mathrm{G}_{\mathrm{s}}=2.66\right)$ was dry pluviated into the container to achieve a relative density $\left(D_{\mathrm{r}}\right)$ of approximately 55\%. While slight variations in soil $D_{\mathrm{r}}$ were expected across the model after preparation, these variations were not closely monitored at all locations. Recordings of cone penetration and bender elements were obtained at limited locations after spinning and prior to each shaking event. But these measurements could not provide insight into local variations in soil's initial properties across the model. The soil surface was leveled at the elevations corresponding to instrumentation or a structure. The soil densified slightly after each earthquake motion, which should be considered in subsequent numerical simulations of the centrifuge tests. The change in relative density after each shaking event was measured by vertical LVDTs placed at different locations throughout the model specimen. 


\section{Instrumentation and Measurements}

Figure 13 provides the detailed instrumentation layout of two representative experiments with a building and an underground structure present (i.e., E-Midrise and T-Highrise). Figure 14 shows a picture of T-Highrise after model construction with all instrumentation in place. Experimental measurements included accelerations and racking deformations of the box structure in relation to the soil in the freefield, settlement patterns across the container after each motion, seismic lateral earth pressures, bending strains and moments on the walls of the underground structures, and axial forces on the excavation struts. Building base shear, bending strains and moments on the basement walls, and the moment-rotation behavior of the beam and column fuses were also monitored during different scenario earthquakes.

Four types of sensors were employed on the two underground structures: accelerometers, linear potentiometers (LPs), strain gauges, and tactile pressure sensors. Analog cameras were also used to monitor the experiment and the movement of the cone penetration device into soil before and after testing. Miniature ICP accelerometers with a measurement range of $100 \mathrm{~g}$ were placed horizontally (in the direction of shaking) within the soil in the far-field and near-field, on the tunnel walls, LP holders, container frames, and the shake table. Double integration of these accelerations could also provide transient lateral displacement time histories at different locations. Vertical accelerometers were placed on the tunnel and container base at the two ends to monitor rocking.

LPs were used to measure settlement in the far-field and near-field at different elevations as well as the tunnel. Racking displacement of the permanent box structure was measured directly by four LPs that were mounted on a bracket attached to the bottom of the tunnel from inside, as shown in Figure 15a. In this way, LPs provided direct measurements of the lateral displacement of the roof of the tunnel with respect to its base. Horizontal LPs were placed at the top and bottom of the braced excavation, which were connected to longer holders attached from the top to the instrumentation rack, as shown in Figure 15b. These longer LP holders were reinforced to minimize their independent vibration and bending. Accelerometers were placed next to each LP, as shown in Figure 15, to monitor the independent movement of the LP holders. In some cases, these accelerometers indicated a small degree of independent 
vibration, which affected the LP recordings. No permanent displacement was expected on structures (e.g., all structures were designed not to yield). Therefore, transient displacements obtained indirectly from accelerometers were judged more reliable and consistent in this case.

Tactile pressure sensors (Tekscan 2012) were used to measure static and dynamic lateral earth pressures on the tunnel walls. Tactile pressure sensors are flexible, thin sheets containing a matrix of sensels (sensors), allowing them to measure pressure distributions without soil arching effects. A tactile sensor containing a matrix of $14 x 14$ sensels with a sampling rate of 4000 samples/sec/sensel was selected to avoid under-sampling in the high frequency environment of the centrifuge. These sensors require deairing, static calibration, conditioning, and equilibration before use. Additionally, in order to use tactile sensors in the presented dynamic centrifuge experiments, the authors developed a new dynamic calibration procedure to characterize their frequency-dependent response and compensate for their underestimation of dynamic earth pressures at higher frequencies (Dashti et al. 2012 and Gillis et al. 2015).

Strain gauges were placed around the tunnel and excavation walls in two arrays in a half-bridge configuration to measure bending. Each array was placed $16 \mathrm{~cm}$ away from the center of the underground structure along its length (or along container width). Bending strains on underground structures were used to indirectly obtain static and dynamic bending moments and lateral earth pressures since a reliable measurement of lateral earth pressures is difficult in centrifuge tests (e.g., Olson et al. 2010; Gillis et al. 2015). Strain gauges were also installed on four strut arrays inside temporary excavations in a full-bridge configuration to measure static and dynamic axial strains and forces acting on the struts. This provided apparent earth pressures on the excavation walls as described by Jones (2015).

The building base shear, inter-story drift, and moment-rotation behavior of columns and beams at fuse locations (if applicable) needed to be monitored during different earthquake events in addition to bending strains and accelerations on the basement walls. Building base shear was indirectly evaluated through the recordings of accelerometers on structural masses and base plates (see Figure 13) multiplied by the corresponding masses. Permanent and transient drifts were measured directly by horizontal LPs 
placed on each structural mass and base plate, which were connected to LP holders attached to an external rack. Due to the large height of the model buildings, however, the LP holders were found to move independently at times. Therefore their independent movements were monitored with accelerometers. The accelerometers could also be used to indirectly obtain transient inter-story drift through doubleintegration, particularly when no permanent drift or yielding was expected. Lastly, to evaluate the moment-rotation behavior at fuse locations, half-bridge strain gauges were placed in the middle of each fuse, as shown in Figure 16.

Four different methods were employed to measure soil properties in flight at locations away from both model structures and container boundaries (far-field array shown in Figure 13): 1) a miniature cone penetration test (CPT); 2) bender element tests; 3) application of a small-amplitude, high frequency sinusoidal motion; and 4) acceleration recordings of centrifuge ambient vibrations. To approximate "freefield" conditions in these experiments, the "far-field" instrumentation array was employed, which was placed halfway between the model structure and container boundary in the direction of shaking.

\section{EVALUATION OF SYSTEM PERFORMANCE}

\section{Base Motions}

It was desirable to achieve realistic earthquake motions that were similar among all six experiments, in order to experimentally evaluate the seismic impact of buildings on adjacent underground structures. The heavy buildings used in these experiments applied an unprecedented demand on the shake table under increased gravity. The impact of this demand on the performance of a servo-hydraulic shake table and the repeatability of achieved motions was a concern, which are evaluated in this section.

A suite of earthquake motions was selected to cover a range of amplitudes, frequency contents, and durations (see Table 4). The dynamic properties of the shaker-model system in relation to the properties of the command signal can significantly influence the characteristics of the achieved base motion by the servo-hydraulic shake table. The desired base motions are often different from those achieved (Mason 2011). After converting the desired motion to model scale units, a high-pass, fifth-order, acausal Butterworth filter at a corner frequency of $10 \mathrm{~Hz}$ (in model scale) was used to limit displacements to the 
shaker's stroke and to remove energy at the first mode of the centrifuge (near $5 \mathrm{~Hz}$ ). Frequencies between 14 to $24 \mathrm{~Hz}$ and 95 to $115 \mathrm{~Hz}$, which corresponded to the higher modes of the centrifuge, were also removed. Lastly, a low-pass filter with a corner frequency of $400 \mathrm{~Hz}$ was used to remove content beyond the controllable bandwidth of the shake table. The resulting acceleration time history was then numerically double integrated to obtain the command signal in terms of the relative displacement between the shake table and centrifuge platform. A general transfer function (TF) developed by Mason (2011) was then applied to the command signal to boost its high-frequency content and improve the match between the achieved and desired base motions.

The command signals had little to no content at frequencies below $10 \mathrm{~Hz}$ and between 14 to $24 \mathrm{~Hz}$ in model scale due to filtering (periods greater than $6.5 \mathrm{~s}$ and between 2.7 and $4.6 \mathrm{~s}$ in prototype scale at $65 \mathrm{~g}$ ). As a result, these motions were not expected to excite the highrise building near its fundamental period of approximately $4 \mathrm{~s}$. Therefore, two scaled and processed command signals obtained from the Los Gatos recording of the 1989 Loma Prieta earthquake were added in the highrise tests to produce small motions at periods near 3 to $4 \mathrm{~s}$ without damaging the shaker or centrifuge.

Table 4 presents the properties of the achieved motions (recorded by base accelerometers) in T-No Bldg, and Figure 17 compares their 5\%-damped spectral accelerations, Fourier amplitude spectra, and Arias intensity time histories. Figure 18 shows the Transfer Functions (TF) of the achieved to desired accelerations in T-No Bldg. In general, the achieved base motions were de-amplified greatly compared to those desired, particularly in frequencies ranging from 3 to $10 \mathrm{~Hz}$ in prototype scale with a roughly similar pattern, despite the use of a general-purpose TF developed by Mason (2011) at the same facility. This demonstrates the importance of an experiment-specific shake table calibration.

The presence of the midrise and highrise buildings and different underground structures affected the weight and natural frequency of the container-soil-structure system. The total model weight varied from 15.9 to $18.7 \mathrm{kN}$ in different tests at a centrifugal acceleration of $65 \mathrm{~g}$. As a result, there was a concern about the variation of base motions from test to test. The repeatability of the achieved base motions and their dependence on the dynamic properties of the model was quantified by the coefficient of variation 
(COV) of the recorded base accelerations in different tests. The COV of a given dataset is defined as the ratio of the standard deviation of that dataset to its mean (i.e., COV $=\sigma / \mu$ ). Here, the dataset of interest is the base acceleration measured in different tests, which varies with time and frequency. Therefore, a COV may be calculated for each motion as a function of time or frequency (for a broadband motion), characterizing the repeatability of a motion in different experiments. Figure 19 shows the COV of the Fourier amplitude spectra of each base motion achieved in the six experiments. Overall, the COV values were reasonably low (less than 0.2 ) in the frequency range of interest from approximately 0.1 to $5 \mathrm{~Hz}$ in prototype scale (6.5 to $325 \mathrm{~Hz}$ in model scale), but tended to increase slightly at higher frequencies that are more difficult to reproduce by most shake tables under increased gravity.

\section{Response of Underground Structures}

In order to evaluate the influence of an adjacent tall building on the performance of a permanent or temporary box structure, first the response of the underground structures needed to be evaluated in isolation (T-No Bldg and E-No Bldg) and compared with design in terms of racking stiffness and seismic displacements along their walls. Then the additional seismic demand imposed by the building could be evaluated both in terms of forces and displacements.

After the simplified centrifuge box structure was built, its racking stiffness $\left(\mathrm{K}_{\mathrm{s}}\right)$ was evaluated experimentally at $1 \mathrm{~g}$ for comparison with its design. This was done by clamping the base of the structure and applying a lateral load at the top of the wall. The applied lateral load divided by the measured lateral displacement at the roof provided an experimental measure of $\mathrm{K}_{\mathrm{s}}$, which was then compared with the design value obtained from a frame analysis. The experimental value of $\mathrm{K}_{\mathrm{s}}$ after model calibration was less than design, likely due to an incomplete penetration of welding across the wall thickness. Therefore, small angle aluminum sections were glued to the four inside corners of the box structure covering its full length, to increase $\mathrm{K}_{\mathrm{s}}$. Table 1 shows that the experimentally obtained value of $\mathrm{K}_{\mathrm{s}} \approx 26.6 \mathrm{MN} / \mathrm{m} / \mathrm{m}$ after this modification compared reasonably well with the design value of $25 \mathrm{MN} / \mathrm{m} / \mathrm{m}$. In T-No Bldg, the farfield accelerometer recordings placed half-way between the tunnel and centrifuge boundaries (approximating free-field conditions) at the elevation of roof and base of the tunnel were double 
integrated to obtain $\max \left|\Delta_{\mathrm{FF}}\right|$ during each motion. Accelerometer recordings on the roof and base of the box structure in T-No Bldg were similarly used to obtain $\max \left|\Delta_{\text {Structure }}\right|$. These values are compared with those estimated during design in Figure 2. Both far-field and box structure racking displacements measured were smaller than those estimated during design because of significantly weaker base motions achieved compared to those selected and used in design, as previously discussed. However, the trends were similar to those expected, and the racking ratio $(R)$ values were close to design.

Transient displacements were obtained along the two excavation walls from double integrated accelerometer recordings (see Figure 13) in all tests. Figure 3 shows the minimum and maximum lateral displacements along the excavation walls during the KobeTAK motion as recorded in E-No Bldg and EHighrise compared with those estimated during design with and without a highrise building. During E-No Bldg, the walls deflected more than the design estimates, but overall they followed an expected displacement trend. The Plaxis-2D analyses had indicated no significant change in peak transient wall deflections with the addition of the highrise building. Yet, the measured peak transient displacements reduced slightly in E-Highrise compared to E-No Bldg. This observation was consistent across experiments and motions. This is likely a result of the kinematic constraint provided by the adjacent building and its basement, which was not taken into account in the simplified Plaxis-2D analyses used during design (i.e., modeling the building only as a surcharge load without its added stiffness).

The maximum bending moment and shear stress profiles along the excavation walls as well as maximum axial strut forces were obtained from strain gauges during E-No Bldg and E-Highrise and are compared with the design estimates in Figure 4 under both static and dynamic conditions. The static bending moments and shear stresses along the walls roughly followed an expected pattern in both E-No Bldg and E-Highrise. Dynamically, however, maximum bending moments, shear stresses, and strut loads were significantly less than design below a depth of about $8 \mathrm{~m}$ because of significantly weaker motions achieved compared to design. It must be noted that the presence of an adjacent highrise building was 
observed to amplify seismic forces on the walls and struts of the temporary excavation (e.g., when comparing E-Highrise with E-No Bldg), as was predicted during design.

\section{Response of Model Buildings}

The modal frequencies of the midrise and highrise structures were experimentally measured at $1 \mathrm{~g}$ by fixing their bases and using a hammer to excite them into free vibration. The three modal frequencies of the 3-DOF midrise structure obtained experimentally were in close agreement with the design values, as summarized in Table 3. The highrise structure, however, was initially found to be slightly more flexible than intended (slightly lower fundamental frequency than design). This was likely due to the minor differences between the fabricated connection details and the perfectly-fixed connection assumed in a numerical simulation. The building model was then modified by using adjustable cross bracings to achieve a higher effective stiffness and the design fundamental frequency (summarized in Table 3 and shown in Figure 12). The cross braces were bolted into place once the design natural frequency was achieved. The flexible-base modal frequencies of the two building models were also monitored in flight during each centrifuge experiment using the TF of mass to foundation accelerations, which were consistent with those expected (slightly lower than the corresponding fixed-base values depending on the intensity of shaking).

Similar to the underground structures, horizontal transient displacements on the structure masses were obtained by double integrating the accelerometer recordings to obtain the drift of each story either with respect to the base plate (total drift) or with respect to the story below (inter-story drift). The peak total drift was first obtained on the roof (top story with respect to the base plate) of the midrise structure among all the motions in T-Midrise and E-Midrise. The base shear of the structure was also estimated at the same time and same motion as the sum of the product of different masses and their corresponding acceleration. Figure 6 shows the results compared with the pushover analyses performed during design (Model II). The comparison shows that the midrise building responded as expected (close to design), but the base shear and drift slightly exceeded the ASCE 7-10 design requirement. No evidence of yielding was observed on the fuses from strain gauge measurements or from visual inspection after the test. At the time 
corresponding to peak total roof drift, the inter-story drifts were also calculated for all levels to obtain a time-synchronized profile along the height of the building during T-Midrise and E-Midrise. The results are compared with the design estimates as well as the ASCE 7-10 allowable inter-story drift in Figure 6. The inter-story drifts at the lower two stories were similar to the design values and smaller than the ASCE 7-10 allowable value, while they were greater on the top story (roof). Overall, the building responded roughly as expected, though its dynamic response was slightly softer than predicted under pseudo-static pushover analyses.

The peak total roof drift and the corresponding base shear were evaluated for the highrise structure in a similar manner as the midrise, with the addition of the two Los Gatos motions that were applied during the highrise tests but not included in prior tests nor considered during design. The largest drift recorded on this structure was measured during the stronger Los Gatos motion, as expected, because of its long-period content that loaded the building closer to its yield point. As shown in Figure 11, the highrise structure experienced a slightly larger base shear and smaller roof drift compared to those expected from the pushover analyses. This stiffer response may have been caused by the addition of horizontal braces to match the design natural period experimentally. However, the recorded peak drift and base shear did not exceed the yield point and were still smaller than the TBI design values.

\section{CONCLUSIONS}

This paper describes the developments and approximations needed to physically model and evaluate the influence of mid to highrise buildings on the response of soil and adjacent shallow underground structures during earthquakes in a centrifuge. The buildings modeled in this study were the tallest and heaviest structures tested in a geotechnical centrifuge to date. Simplified, scaled building models needed to be designed that could: 1) be accommodated in the limited space of a centrifuge; 2) avoid a complex and costly fabrication process; 3) provide space for instrumentation, 4) transmit realistic seismic demands onto the underground structures that reflect the modal frequencies, base shear, base moment, and yield characteristics of mid and highrise structures, and 5) achieve realistic and repeatable earthquake motions at the base of the container across all experiments with varying payload weights. 
Medium dense, Nevada sand was dry pluviated into the FSB container to model a 26 m-thick deposit in prototype scale at $65 \mathrm{~g}$. accommodate the tall building model height above the soil surface. The midrise building was simplified from 13-DOFs to 3-DOFs to capture the three primary translational modes of vibration that dominate its inertial response and reduce the number of structural masses to a practical and manageable number in a scaled model with dense instrumentation. It was possible to simulate the height, mass, and three primary modes of a 13-story, midrise building with a simplified, 3-DOF model in the centrifuge. For the 42-story highrise building, due to a limited overhead space, additional simplifications were necessary. Only the fundamental frequency, mass, and therefore base shear of the highrise building could be simulated with a scaled, 1-DOF model in centrifuge, while its base moment and higher modes of response could not be represented. The basement of both structures was designed as an open box filled with soil to maximize the forces transferred to the underground structures.

Although the container was not filled to its capacity, the tall and heavy structures used in these experiments subjected the shake table to an unprecedented payload and friction under increased gravity, which was expected to adversely affect the repeatability of motions. Even though the measured base motions were considerably reduced in amplitude compared to those desired, their coefficient of variation among six experiments was less than 0.2 in the 0.1 to $5 \mathrm{~Hz}$ frequency range, enabling a reliable comparison of experimental results.

The racking stiffness of underground structures and modal frequencies of buildings were obtained experimentally at $1 \mathrm{~g}$ under fixed-base conditions and were consistent with design estimates. During the dynamic centrifuge experiments, the base shear forces and roof drifts were monitored on both midrise and highrise structures, which were consistent with pseudo-static, pushover analyses and building code requirements. Therefore, the generated overall stiffness and yielding characteristics of scaled buildings as well as the seismic shear forces they transferred to the soil reflected the as-designed structures.

The overall response of the system in the presented centrifuge experiments indicates that the seismic forces and moments transferred from tall buildings to the foundation soil and adjacent underground structures can be successfully modeled, measured, and evaluated in a centrifuge, with certain inherent 
approximations. These experiments enable validation of numerical tools, which may later be used to evaluate the seismic response of more realistic soil and structural conditions and the influence of inherent experimental approximations on seismic soil-structure-underground structure-interaction.

\section{ACKNOWLEDGEMENTS}

This work was supported by the NSF under Grant no. 1134968. Any opinions, findings, and conclusions or recommendations expressed in this material are those of the authors and do not necessarily reflect the views of the NSF. We would like to acknowledge the staff and researchers at UCD-CGM, particularly Dr. Dan Wilson, for their valuable feedback during the design and execution of the centrifuge experiments.

\section{REFERENCES}

American Institute of Steel Construction (AISC) (2006). “Steel Construction Manual,” 13th Ed., Sections E and F.

American Society of Civil Engineers (ASCE) ASCE/SEI 7-10 (2013). “Minimum design loads for buildings and other structures”, 636.

Anderson, Donald G., Geoffrey R. Martin, Ignatius Lam, and J. N. Wang (2008). "Seismic analysis and design of retaining walls, buried structures, slopes and embankments," National Cooperative Highway Research Program, Transportation Research Board.

Baldi, G., Bellotti, R., Ghionna, V. N., Jamiolkowski, M. and Lo Presti, D.C.F. (1989). "Modulus of sands from CPTs and DMTs.” Proc., 12th Int. Conf. on Soil Mech. and Foundation Eng., Vol. 1, Rio de Janeiro, 165-170.

Bardet, J.P., Huang, Q., and Chi, S.W. (1993). "Verification of numerical procedures for the analysis of soil liquefaction problems," Proc., Intl. Conf. on the Verification of Num. Procedures for the Analysis of Soil Liquefaction Problems, Davis, Ca., 66-87.

Chen, Z., Trombetta, N. W., Hutchinson, T. C., Mason, H. B., Bray, J. D., and Kutter, B. L. (2013). “Seismic system identification using centrifuge-based soil-structure interaction test data," Journal of Earthquake Engineering, 17(4), 469-496. 
Darendeli, M. (2001). “Development of a new family of normalized modulus reduction and material damping curves.” Ph.D. Thesis, Univ. of Texas, Austin.

Dashti, S., Bray, J.D., Pestana, J.M., Riemer, M.R. and Wilson, D. (2010). "Mechanisms of seismicallyinduced settlement of buildings with shallow foundations on liquefiable soil," J. Geotech. Geoenviron. Eng., 136(1), 151-164.

Divis C.J., Kutter, B.L., Idriss, I.M., Goto,Y., Matsuda, T. (1996). "Uniformity of specimen and response of liquefiable sand model in large centrifuge shaker," Proceedings of the sixth Japan-US workshop on earthquake resistant design of lifeline facilities and countermeasures against soil liquefaction, p.259-74.

Elgamal, A., Yang, Z., Parra, E. (2002). "Computational modeling of cyclic mobility and postliquefaction site response,” Soil Dyn. and Earthquake Eng. Journal, 22(4), 259-271.

Gillis, K., Dashti, S., Hashash Y. (2015). "Dynamic Calibration of Tactile Sensors for Measurement of Soil Pressures in Centrifuge,” ASTM Geotechnical Testing Journal.

Hardin, BO, and VP Drnevich (1972a). "Shear modulus and damping in soils: measurement and parameter effects”, J. Soil Mech. and Foundations Div., SM 6, 603-624.

Hardin, BO, and VP Drnevich (1972b). "Shear modulus and damping in soils: design equations and curves”, J. Soil Mech. and Foundations Div., SM 7, 667-692.

Hashash, Y., Dashti, S., Romero Arduz, M.I., Ghayoomi, M., Musgrove, M. (2015a). “Evaluation of 1-D seismic site response modeling of sand using centrifuge experiments,” Soil Dyn. and Earthquake Eng. Journal, 78, 19-31.

Hashash, Y. M. A., M. I. Musgrove, J. A. Harmon, D. Groholski, C. A. Phillips and D. Park (2015b). “DEEPSOIL V6.0, User Manual.” Urbana, IL, Board of Trustees of University of Illinois at UrbanaChampaign.

Hashash, Y.M.A., Karina, K., Koutsoftas, D., O’Riordan, N. (2010). Seismic design considerations for underground box structures, Earth Retention Conf., Bellevue, Wa., 620-637. 
Hashash, Y.M.A., Hook, J.J., Schmidt, B., and Yao, J.I. (2001). "Seismic design and analysis of underground structures,” Tunneling and Underground Space Technology, 16, 247-293.

Jamiolkowski, M.,Leroueil, S., and LoPresti, D.C.F. (1991). “Theme lecture: Design parameters from theory to practice.” Proc., Geo-Coast ’91, Yokohama, Japan, 1-41.

Jones, C. (2015). "Interpretation of centrifuge test results of the seismic response of temporary braced excavations near tall buildings,” Master's thesis, Dept. of Civil, Environmental, and Architectural Engineering, University of Colorado, Boulder.

Martin, G. and Lam, I.P. (2000). "Earthquake resistant design of foundation-retrofit of existing foundations,” Proc., GeoEngineering 2000 Conf., Melbourne, Australia.

Mikola, R. G. (2012). “Seismic Earth Pressures on Retaining Structures and Basement Walls in Cohesionless Soils,” Ph.D. Dissertation, University of California at Berkeley.

Mason, H.B. (2011). “Seismic performance assessment in dense urban environments," Ph.D. Dissertation, Univ. of California, Berkeley.

Mason, H. B., Trombetta, N. W., Bray, J. D., Chen, Z., Hutchinson, T. C., and Kutter, B. L. (2013). “Soilfoundation-structure interaction of shallowly embedded footings supporting inelastic frame structures,” Soil Dynamics and Earthquake Engineering 48, 162-174.

Mazzoni, S., McKenna, F., Scott, M., and Fenves, G. (2006). “Open system for earthquake engineering simulation user command-language,” Network for Earthquake Engineering Simulations (NEES), Berkeley, CA.

Menq, F. -Y. (2003). “Dynamic properties of sandy and gravely soils,” Ph.D. Dissertation, Univ. of Texas at Austin.

Moehle, Y. B., Jayaram, N., Jones, P., Rahnama, M., Shome, N., Tuna, Z., Walace, J., Yang, T.Y., Zareian, F. (2011), “Case studies of the seismic performance of tall buildings designed by alternative means,” Pacific Earthquake Engineering Research Center, University of California, Berkeley. Report number 2011/05. 
Olson, S. M., Hashash, Y. M. A., Muszynski, M. R., Phillips, C., and Polito, C. (2010), “Using Tactile Pressure Sensors to Measure Lateral Spreading-Induced Earth Pressures Against a Large, Rigid Foundation,” Proc. of the 5th Int. Conf. on Recent Advances in Geotechnical EQ Eng. and Soil Dyn., S. Prakash, Ed., San Diego, CA, May 24-29, pp. 1-10.Pecker, A. and Pender, M. (2000). "Earthquake resistant design of foundations: new construction,” Proceedings of GeoEngineering 2000 Conf., Melbourne, Australia, 313-334.

Piratheepan, P. (2002). Estimating shear-wave velocity from SPT and CPT data. M.S. Thesis, Clemson University.

Pitilakis, K., Kirtas, E., Sextos, A., Bolton, M., Madabhushi, G., and Brennan, A. (2004). "Validation by centrifuge testing of numerical simulations for soil-foundation-structure systems," Proc. of 13th World Conf. Earthquake Eng., Vancouver, Canada.Seed, H.B. and Idriss, I.M. (1970). "Soil moduli and damping factors for dynamic response analyses,” Report EERC 70-10, Earthquake Engineering Research Center, University of California, Berkeley.

Stewart, D.P., Idriss, I.M., Boulanger, R.W., Hashash, Y., Schmidt, B. (1999). “Mitigation of earthquake liquefaction hazards: a review of physical modeling studies,” Proc., 8th Australia New Zealand Conf. on Geomechanics, Hobart, Tasmania, V. 1, 337-343.

Tekscan Inc. (2012), “I-Scan \& High-Speed I-Scan User Manual v. 7.5x,” Tekscan Inc., Boston, MA.

Trombetta, N.W., Mason, H.B., Chen, Z., Hutchinson, T.C., Bray, J.D., and Kutter, B.L. (2013). "Nonlinear dynamic foundation and frame structure response observed in geotechnical centrifuge experiments,” Soil Dynamics and Earthquake Engineering 50, 117-133.

Whitman RV, Lambe PC. (1986). "Effect of boundary conditions upon centrifuge experiments using ground motion simulation,” ASTM Geotechnical Testing Journal, 9(2), 61-71.

Yang, Z. (2000). “Numerical modeling of earthquake site response including dilation and liquefaction,” Ph.D. thesis, Columbia University. 
Table 1. Properties of the designed single-box tunnel structure compared to the simplified centrifuge model (prototype scale at 65g of centrifugal acceleration).

\begin{tabular}{|c|cc|}
\hline & $\begin{array}{c}\text { Design } \\
\text { Properties }\end{array}$ & $\begin{array}{c}\text { Centrifuge Model } \\
\text { Properties }\end{array}$ \\
\hline Height (m) & 8 & 8 \\
Width (m) & 14 & 14 \\
Wall Thickness (m) & 0.8 & 0.57 \\
Material Type & Reinforced & 6061 Aluminum \\
Concrete & 2700 \\
Density (kg/m ${ }^{3}$ ) & 2400 & $6.89 \mathrm{E}+07$ \\
Young's Modulus & $2.50 \mathrm{E}+07$ & 0.33 \\
Poisson's Ratio & 0.2 & 25 (frame anal.), \\
Racking Stiffness & 25 (frame & 26.6 (experiment) \\
(MN/m/m) & anal.)
\end{tabular}


Table 2. Properties of the designed temporary excavation compared to the simplified centrifuge model excavation (prototype scale).

\begin{tabular}{|c|c|c|}
\hline & $\begin{array}{c}\text { Design } \\
\text { Properties }\end{array}$ & $\begin{array}{c}\text { Centrifuge } \\
\text { Model Properties }\end{array}$ \\
\hline Height (m) & 18 (6 embedded) & 18 (6 embedded) \\
\hline Width (m) & 14 & 14 \\
\hline Material Type & Steel & $6061 \mathrm{Al}$. \\
\hline Wall Beams & $\begin{array}{l}\text { W27x146 (horiz. } \\
\text { spacing: } 1.5 \text { m) }\end{array}$ & $0.41 \mathrm{~m}$ thick plate \\
\hline Struts & $\begin{array}{l}\text { HSS14x0.625 } \\
\text { (spacing: } 4.2 \mathrm{~m} \\
\text { horiz.; } 2-3-3 \mathrm{~m} \\
\text { vert. from top) }\end{array}$ & $\begin{array}{l}\text { OD-0.41m, ID- } \\
\text { 0.39m (spacing: } \\
\text { 4.2m horiz.; 3-3-3m } \\
\text { vert. from top) }\end{array}$ \\
\hline Density $\left(\mathrm{kg} / \mathrm{m}^{3}\right)$ & 7800 & 2700 \\
\hline Young's Mod. (kPa) & $2.50 \mathrm{E}+07$ & $6.89 \mathrm{E}+07$ \\
\hline Poisson’s Ratio & 0.28 & 0.33 \\
\hline $\begin{array}{l}\text { Racking Stiffness } \\
(\mathrm{MN} / \mathrm{m} / \mathrm{m})\end{array}$ & 1.47 & 1.5 \\
\hline
\end{tabular}


Table 3. Properties of midrise and highrise buildings as designed and simplified for centrifuge modeling.

\begin{tabular}{|c|c|c|c|c|c|c|}
\hline & \multirow{2}{*}{$\begin{array}{c}\text { Design } \\
\text { Properties } \\
\text { Target Range }\end{array}$} & \multicolumn{2}{|c|}{ Centrifuge Model Properties } & \multirow{2}{*}{$\begin{array}{c}\text { Design } \\
\text { Properties } \\
\text { Target Range }\end{array}$} & \multicolumn{2}{|c|}{$\begin{array}{l}\text { Centrifuge Model } \\
\text { Properties }\end{array}$} \\
\hline & & $\begin{array}{l}\text { Prototype } \\
\text { Dimensions }\end{array}$ & $\begin{array}{c}\text { Model } \\
\text { Dimensions } \\
\mathrm{N}=65\end{array}$ & & $\begin{array}{c}\text { Prototype } \\
\text { Dimensions }\end{array}$ & $\begin{array}{c}\text { Model } \\
\text { Dimension } \\
\text { s N=65 }\end{array}$ \\
\hline Number of Stories & 13 to 15 & $\begin{array}{c}13 \text { simulated } \\
\text { with } 3 \text { masses }\end{array}$ & $\begin{array}{l}3 \text { mass } \\
\text { system }\end{array}$ & 42 & $\begin{array}{l}42 \text { simulated } \\
\text { with } 1 \text { mass }\end{array}$ & $\begin{array}{l}1 \text { mass } \\
\text { system }\end{array}$ \\
\hline Subterranean Levels & 1 to 2 & 1 & 1 & 4 & 4 & 4 \\
\hline $\begin{array}{l}\text { Seismic Structural } \\
\text { System }\end{array}$ & $\begin{array}{l}\text { RCMF or } \\
\text { SMRF }\end{array}$ & SMRF & SMRF & $\begin{array}{l}\text { Concrete core } \\
\text { with SMRF }\end{array}$ & SMRF & SMRF \\
\hline $\begin{array}{l}\text { Height Above } \\
\text { Ground (m) }\end{array}$ & 50 to 70 & $48.75^{(2)}$ & $0.75^{(2)}$ & 142 & $48.75^{(2)}$ & $0.75^{(2)}$ \\
\hline $\begin{array}{l}\text { Depth below } \\
\text { Ground (m) }\end{array}$ & 4.5 to 6.5 & 4.25 & 0.065 & 13 & 13 & 0.2 \\
\hline $\begin{array}{l}\text { Footprint Dim. } \\
(\mathrm{m} \times \mathrm{m})\end{array}$ & $\begin{array}{c}23 \times 59 \text { / 53x53 } \\
\text { / 38.5x22.5 }\end{array}$ & $38.5 \times 22.5^{(2)}$ & $\begin{array}{l}0.592 \mathrm{x} \\
0.346^{(2)}\end{array}$ & $\begin{array}{l}\text { Bldg: } 69 \text { x } \\
\text { 69; } \\
\text { Core: } 33 \text { x } 33\end{array}$ & $33 \times 33$ & $\begin{array}{c}0.508 x \\
0.508\end{array}$ \\
\hline $\begin{array}{l}\text { Seismic Weight } \\
\text { Density } \\
\left(\mathrm{kN} / \mathrm{m}^{2} / \text { story }\right)\end{array}$ & $\begin{array}{l}\text { RCMF: } 7.13 \text {; } \\
\text { SMRF: } 3.5 \text { to } \\
\quad 3.81\end{array}$ & 3.5 & - & $\begin{array}{l}\text { Bldg. } \\
\text { footprint: } \\
\text { 2.27; Core } \\
\text { footprint: } \\
9.92\end{array}$ & 9.92 & - \\
\hline $\begin{array}{l}\text { Weight of } \\
\text { Superstructure }(\mathrm{kN})\end{array}$ & $\begin{array}{c}42,860 \text { to } \\
125,743\end{array}$ & 39,414 & 0.192 & 453,719 & 453,719 & 1.77 \\
\hline $\begin{array}{l}\text { Fundamental } \\
\text { Periods (sec) }\end{array}$ & $\begin{array}{c}\text { RC: 2.6-2.7; } \\
\text { SMRF: } \\
\text { 3.03/1.08/0.65; } \\
\text { 1.69/0.56/0.32 }\end{array}$ & $\begin{array}{c}3.02 / 0.85 / 0.43 \\
\text { (3) }\end{array}$ & $\begin{array}{c}3.35 / 0.84 / 0 \\
43^{(5)}\end{array}$ & 4.28 to 4.93 & 4.03 & - \\
\hline Base Shear $(\mathrm{kN})$ & $\begin{array}{l}\mathrm{V}_{\mathrm{y}} / \mathrm{W}=0.088 \\
\quad \text { to } 0.094\end{array}$ & $\begin{array}{l}\text { Demand: 3,510; } \\
\text { Yield: 3,510 }\end{array}$ & - & $\begin{array}{l}\text { Demand: } \\
47,738\end{array}$ & $\begin{array}{l}\text { Yield: } \\
57,858^{(4)}\end{array}$ & - \\
\hline Max. Drift Ratio (m) & 0.44 to 0.52 & $0.15^{(3)}$ & & N.A. & N.A. & N.A. \\
\hline $\begin{array}{l}\text { Overturning } \\
\text { Moment (kN-m) }\end{array}$ & $\begin{array}{l}\text { Yield: } 188,584 \\
\text { to } 827,389\end{array}$ & $\begin{array}{c}\text { Demand: } \\
\text { 167,602; } \\
\text { Yield: 167,602 }\end{array}$ & - & $\begin{array}{l}\text { Demand: } \\
1,057,538\end{array}$ & $\begin{array}{l}\text { Yielding: } \\
\text { 2,820,580 }\end{array}$ & - \\
\hline $\begin{array}{l}\text { Column and Beam } \\
\text { Model Sections }\end{array}$ & N.A. & N.A. & $\begin{array}{l}\text { HSS 5/8” x } \\
5 / 8 ” \times 1 / 16 ”\end{array}$ & N.A. & N.A. & $\begin{array}{l}\operatorname{HSS} 3 / 2 \times \\
3 / 2 \times 1 / 8 ”\end{array}$ \\
\hline $\begin{array}{l}\text { Basement Wall } \\
\text { Sections (m) }\end{array}$ & N.A. & $\begin{array}{c}\mathrm{H}=10 \mathrm{~m}, \mathrm{Th} .= \\
0.2 \mathrm{~m}\end{array}$ & $\begin{array}{l}\mathrm{H}=154 \mathrm{~mm} \\
\text { Th. }=3.2 \mathrm{~mm}\end{array}$ & N.A. & $\begin{array}{l}\mathrm{H}=200 \mathrm{~mm} \\
\text { Th. }=9.5 \mathrm{~mm}\end{array}$ & $\begin{aligned} H & =13 \mathrm{~m} \\
\text { Th. } & =0.6 \mathrm{~m}\end{aligned}$ \\
\hline
\end{tabular}

NOTE: ${ }^{(1)}$ RCMF: Reinforced Concrete Moment Frame, SMRF: Steel Moment Resisting Frame;

${ }^{(2)}$ Due to centrifuge size limitations;

(3) Estimated using a 2D OpenSees model to meet seismic demand and allowable drift requirements from ASCE7-10 for the building properties selected;

(4) Estimated using a 2D OpenSees model to the demands estimated for the prototype building;

(5) Found experimentally using a hammer impact test;

(6) Not provided in the literature found. 
Table 4. Properties of the achieved base motions in T-No Bldg (shown in prototype scale and in the sequence they were applied).

\begin{tabular}{|llcccccc|}
\hline Source Event & Source Station & $\begin{array}{c}\text { PGA } \\
(\mathrm{g})\end{array}$ & $\begin{array}{c}\text { PGV } \\
(\mathrm{cm} / \mathrm{s})\end{array}$ & $\begin{array}{c}\text { PGD } \\
(\mathrm{cm})\end{array}$ & $\mathrm{I}_{\mathrm{a}}(\mathrm{m} / \mathrm{s})$ & $\mathrm{D}_{5-95}(\mathrm{~s})$ & $\mathrm{T}_{\mathrm{p}}(\mathrm{s})$ \\
\hline Northridge 1994 & Newhall - WPC & 0.46 & 49.4 & 12.1 & 1.0 & 6.2 & 2.2 \\
Loma Prieta 1989 & Santa Cruz - L. Obs. & 0.1 & 10.5 & 0.6 & 0.1 & 11.3 & 0.6 \\
Landers 1992 & Joshua Tree & 0.25 & 21.8 & 4.4 & 1.8 & 27.5 & 0.7 \\
Chi Chi 1999 & TCU078 & 0.34 & 26.9 & 5.0 & 2.5 & 26.8 & 0.7 \\
Landers 1992 & Lucerne & 0.38 & 32.6 & 6.8 & 1.0 & 9.6 & 0.7 \\
Kobe 1995 & Takatori & 0.45 & 52.8 & 16.2 & 3.4 & 11.6 & 1.3 \\
Northridge 1994 & Newhall - WPC & 0.49 & 56.6 & 16.0 & 1.4 & 9.1 & 2.2 \\
Loma Prieta 1989 & Los Gatos & 0.04 & 9.2 & 3.1 & 0.0 & 8.0 & 4.1 \\
Loma Prieta 1989 & Los Gatos & 0.07 & 18.0 & 6.3 & 0.1 & 8.1 & 4.1 \\
\hline
\end{tabular}




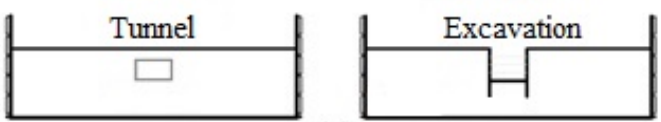

(a)

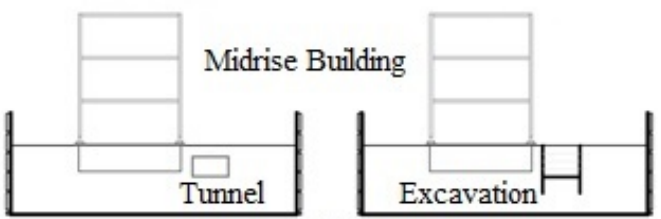

(b)

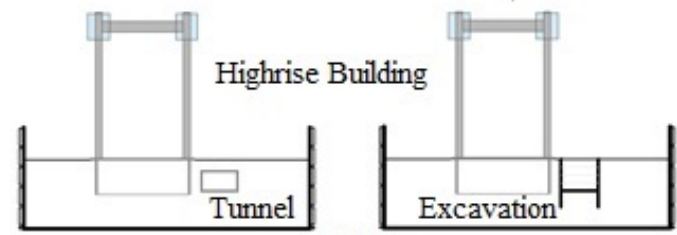

(c)

Figure 1. Schematic drawing of the centrifuge testing plan: a) T-No Bldg and E-No Bldg: permanent tunnel box structure and braced excavation in medium dense, dry Nevada sand and no adjacent building present; b) T-Midrise and E-Midrise: tunnel and braced excavation each near a model midrise building; c)

T-Highrise and E-Highrise: tunnel and braced excavation each near a model highrise building. 


\section{LomaSCZ $\square$ LandersJOS $\square$ ChiTCU $\square$ LandersLCN $\square$ NorthridgeWPI $\square$ KobeTAK}

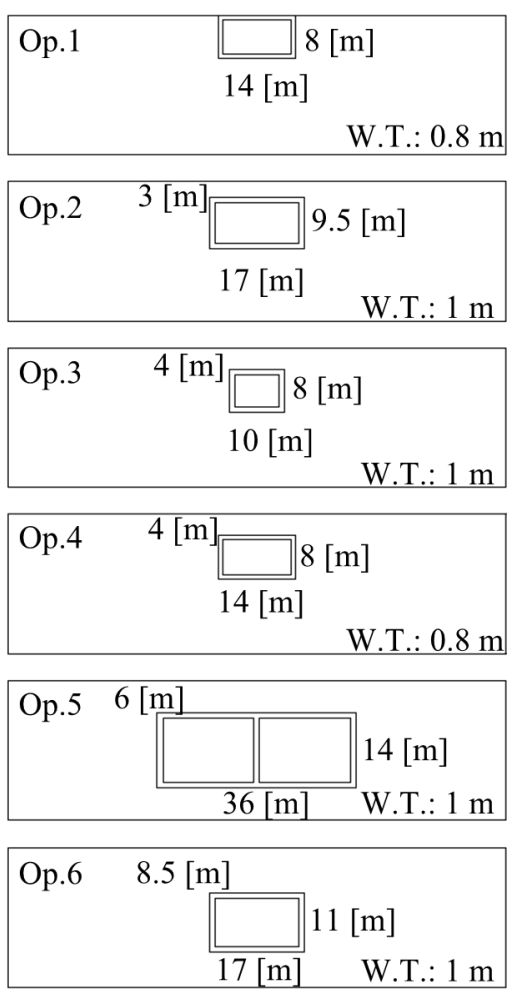

W.T.: Wall thickness

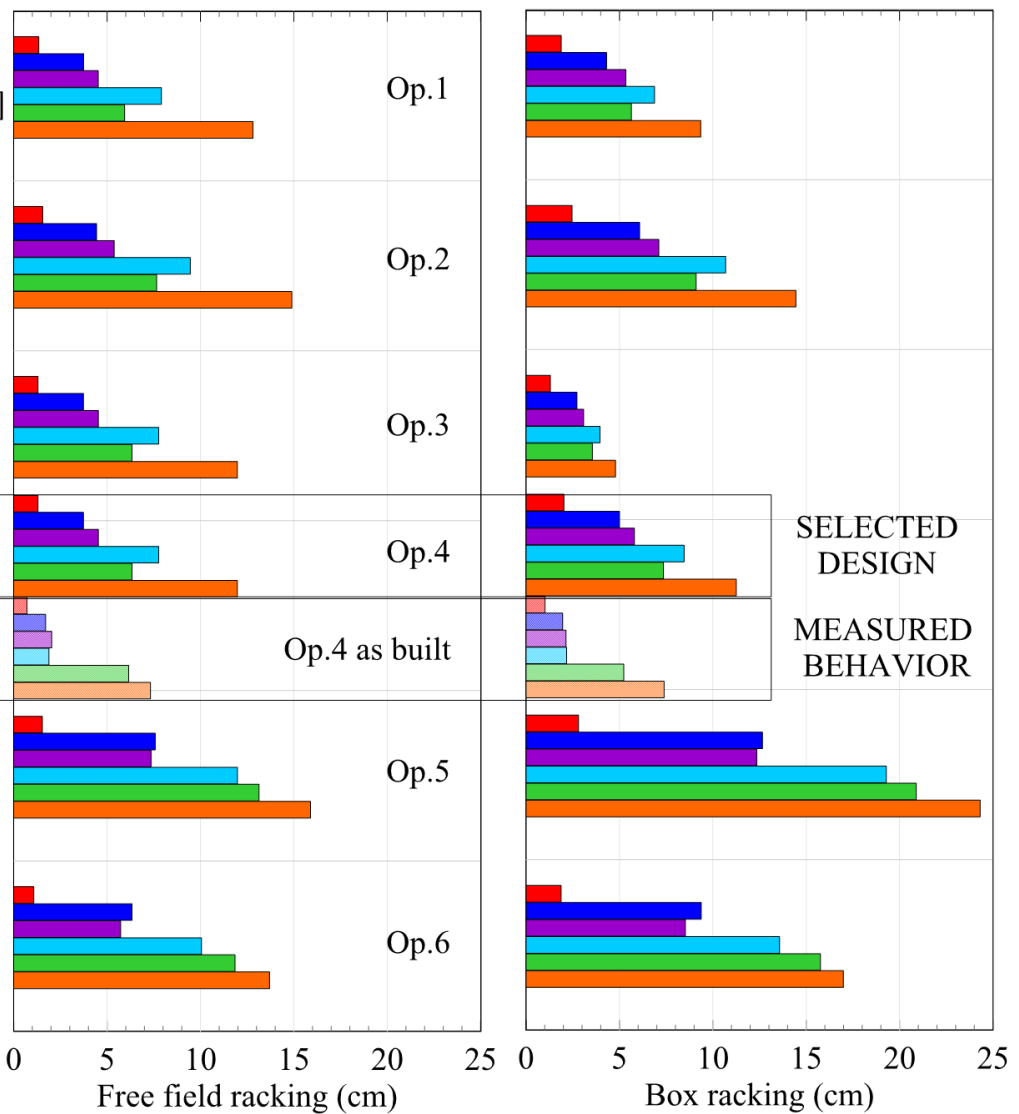

Free field racking $(\mathrm{cm})$

Original design (Op.1 to 6): Max \{OpenSees, Deepsoil Nonlinear, Deepsoil Eq. Linear, Centrifuge CU Boulder\} Measured behavior (Op.4 as built): Max $\{$ T-NoBldg Free field and Box Centrifuge measurements $\}$

Figure 2. Options considered for the design of the permanent box tunnel structure based on the maximum free-field and box racking displacements according to the NCHRP 611 procedure and compared with the measured behavior in T-No Bldg for the selected Option 4. 

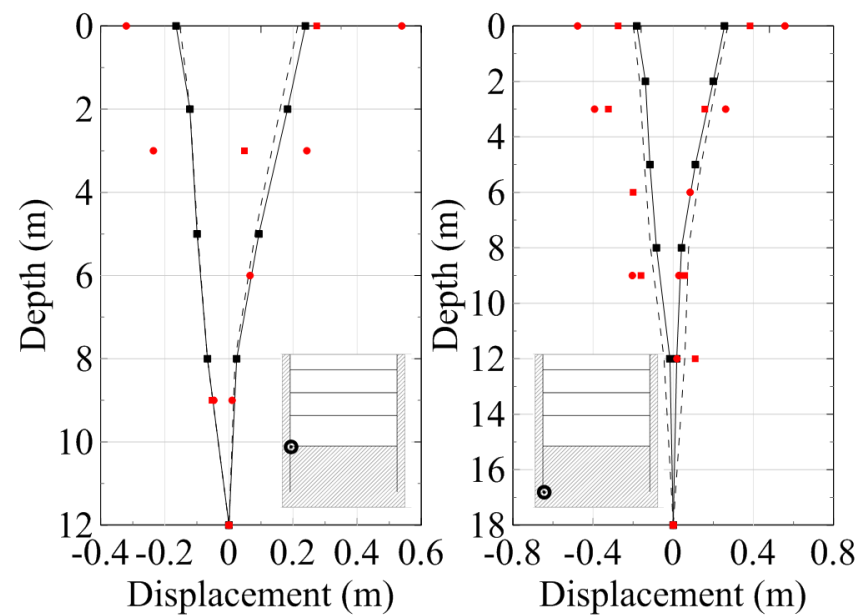

-- Excavation only
- Excavation and highrise
- Measurements E-No Bldg
- Measurements E-Highrise

Figure 3. Maximum and minimum transient lateral displacement profiles of the two excavation walls during the KobeTAK motion as computed by Plaxis-2D during design and as measured in centrifuge with and without the adjacent highrise building (left: with respect to the bottom of the excavation; and right: with respect to the bottom of the wall). 


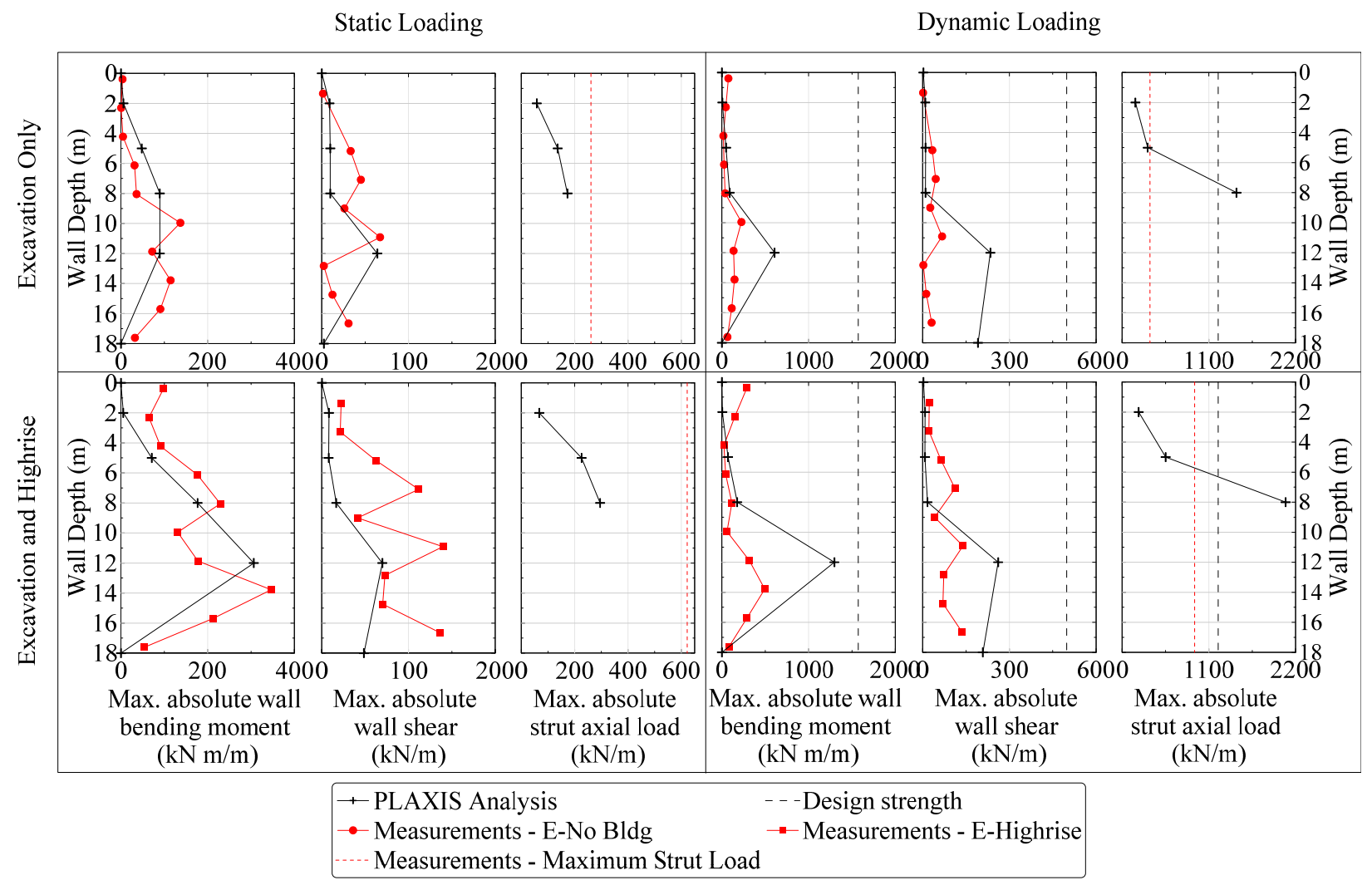

Figure 4. Maximum absolute forces on the excavation wall and struts under static and dynamic conditions computed in the Plaxis2D finite element simulations compared with the corresponding design strengths and the actual measurements in centrifuge in E-No Bldg and E-Highrise. 

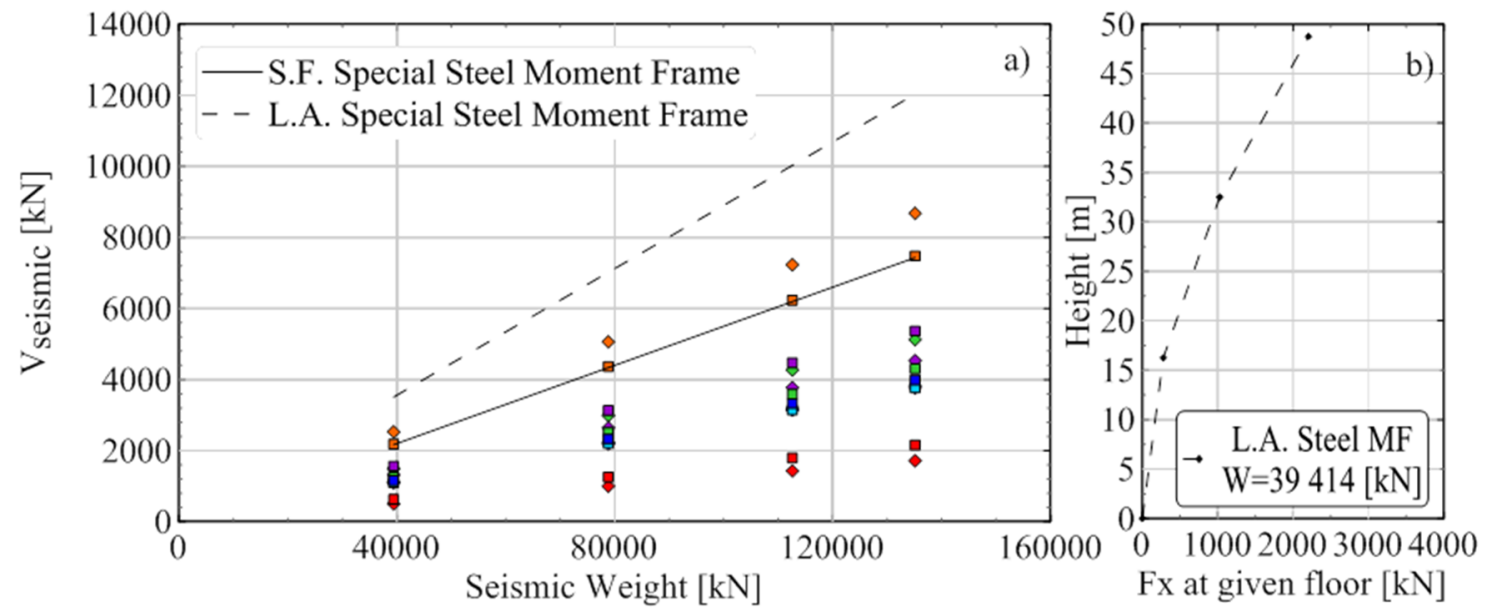

Centrifuge base: $\quad$ NorthridgeWPI $\bullet$ LomaSCZ $\bullet$ LanderLCN $\diamond$ LanderJOS $\bullet$ KobeTAK $\bullet$ ChiTCU $\bullet$ Centrifuge surface: NorthridgeWPI $\square$ LomaSCZ - LanderLCN $\square$ LanderJOS - KobeTAK $\square$ ChiTCU -

Figure 5: a) Seismic shear demand estimated using ASCE 7-10 for a 13 story building placed in LA or SF compared with seismic shear expected in the UCD-CGM centrifuge tests for different seismic weights; b) distribution of load demand per floor from the ASCE 7-10 Equivalent Lateral Force Analysis for the selected weight (masses lumped at three levels). 


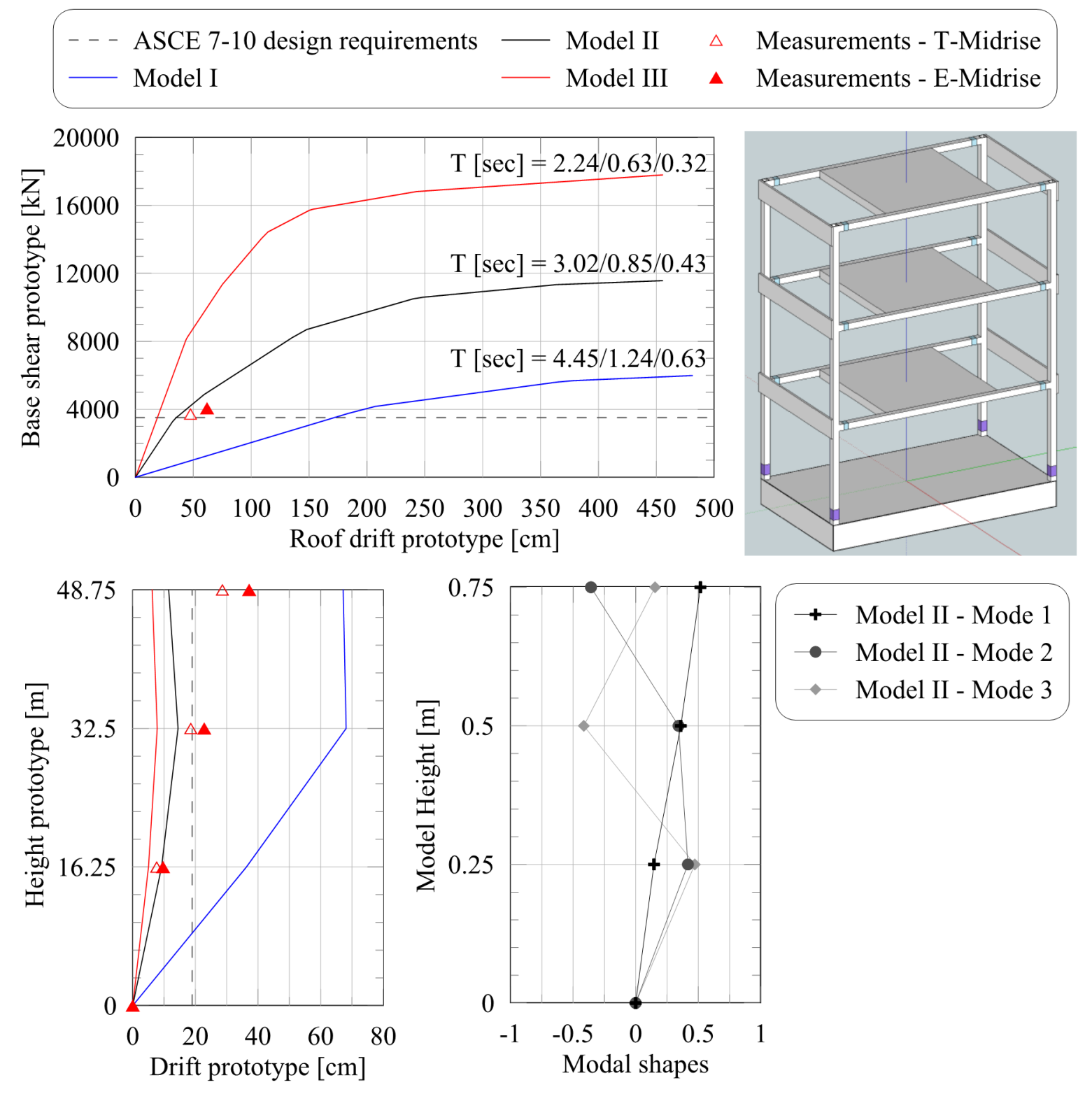

Figure 6: Static pushover analysis and modal analysis results in OpenSees to select the structural properties of a midrise building model for centrifuge testing compared with actual measurements of peak drift and base shear during T-Midrise and E-Midrise. 


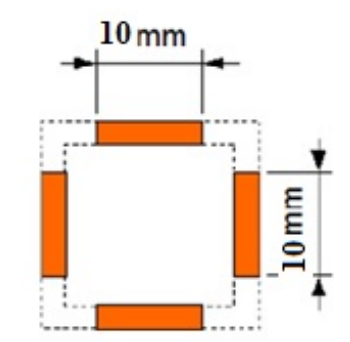

Beam fuse; Length: $12.7 \mathrm{~mm}$

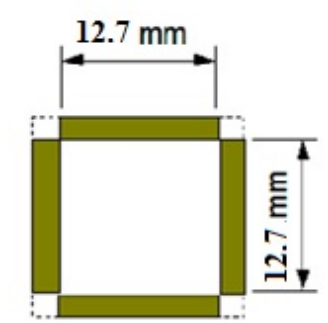

Column fuse; Length: 25.4 $\mathrm{mm}$

Figure 7: Fuses designed on the beams and columns of the midrise structure. 


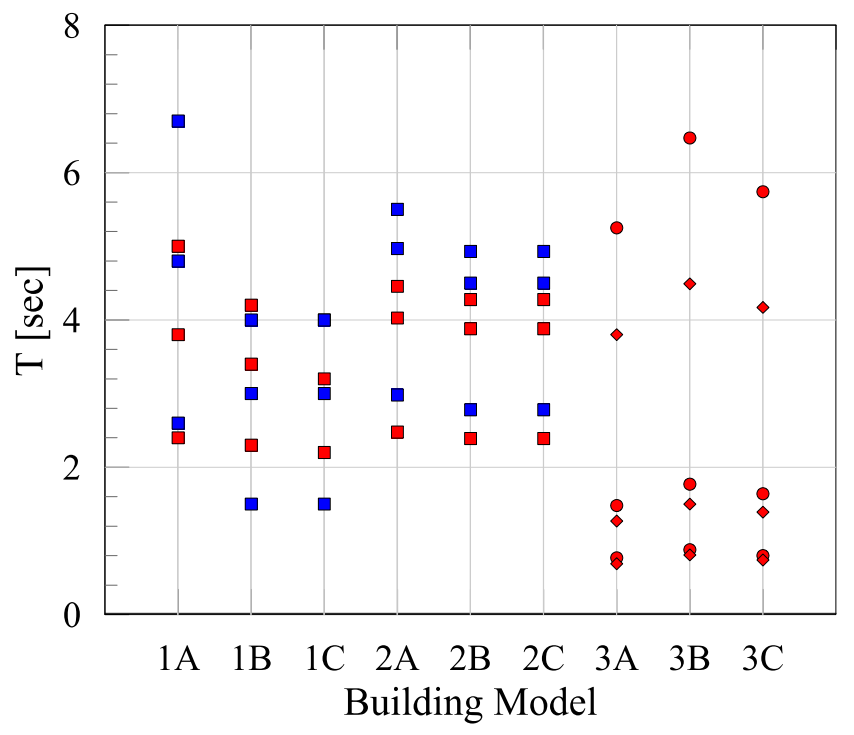

- ETABS Perform3D - Dir.x

- Perform3D - Perform3D - Dir.y

Figure 8: Summary of fundamental periods expected for a 42 story building from PEER 2011/05 - Case Studies of the Seismic Performance of Tall Buildings Designed by Alternative Means (Moehle et al. 2011) 

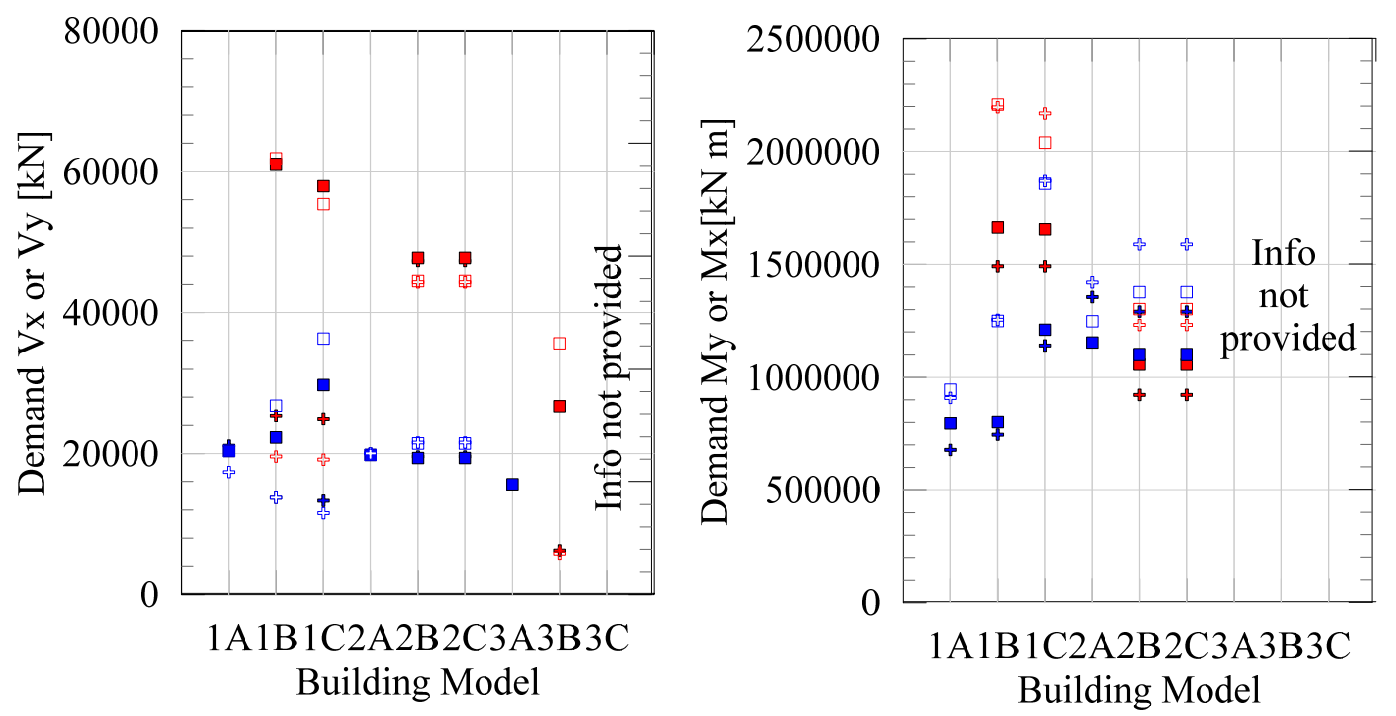

Vx or My: Service Eq.- Grade level - MCE-Grade Level - Service Eq.- Basement level + MCE- Basement level + Vy or Mx: Service Eq.- Grade level $\square$ MCE-Grade Level $\square$ Service Eq.- Basement level MCE- Basement level

Figure 9: Summary of seismic demand expected for a 42 story building - Case Studies of the Seismic Performance of Tall Buildings Designed by Alternative Means (Moehle et al. 2011). 


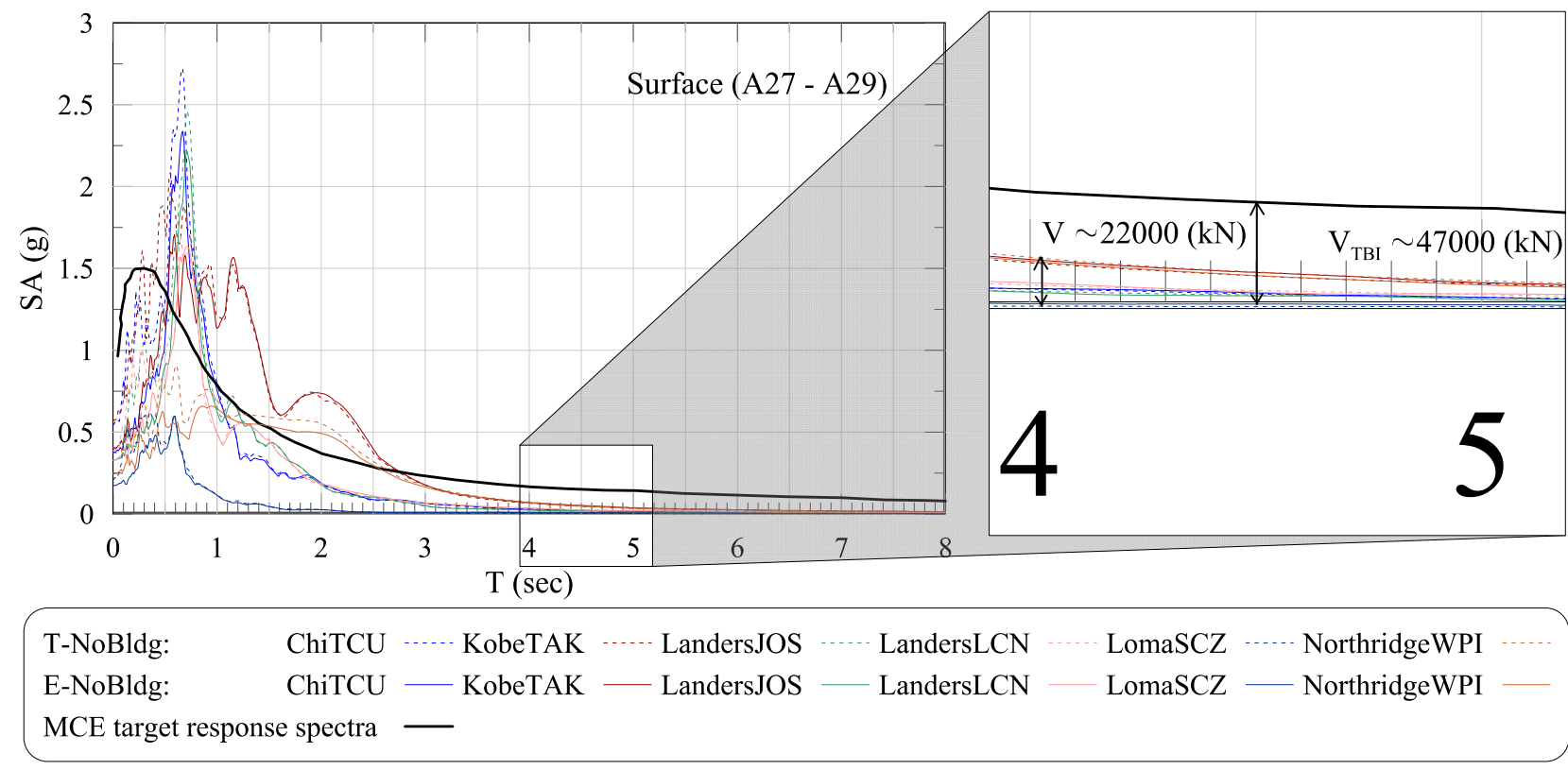

Figure 10: Measured acceleration response spectra (5\% damped) at the soil surface in the far-field in TNo Bldg and E-No Bldg compared with the TBI MCE level target acceleration response spectrum used in the design of the highrise building. 

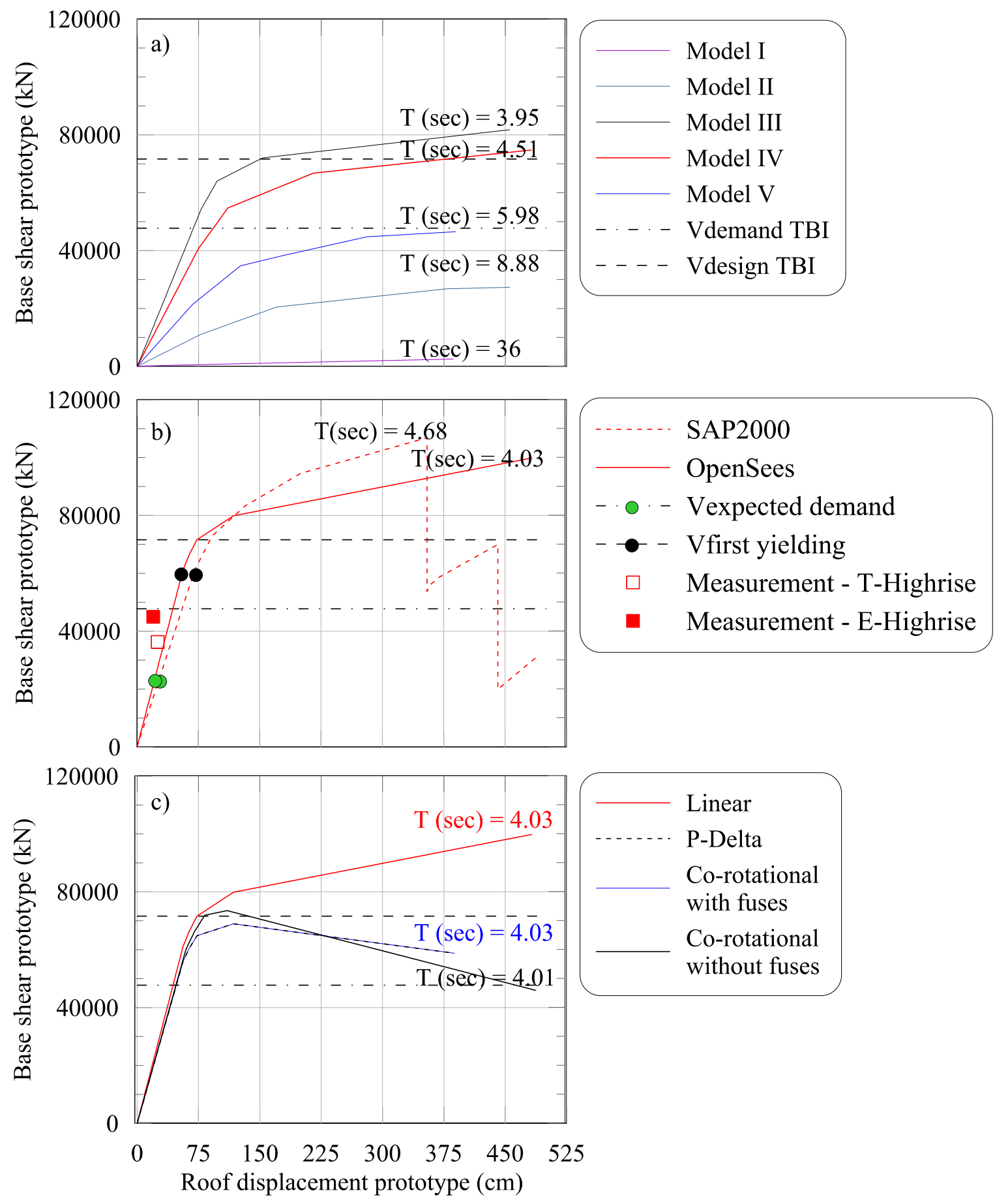

Figure 11: Pushover analysis results for the highrise building model design: a) OpenSees first set of analyses to achieve target parameters (Model IV); b) comparison of results from OpenSees and SAP2000 for the final design with measured values of peak drift and base shear during T-Highrise and E-Highrise;

c) verification of the final design by varying the element's geometric transformation in OpenSees. 


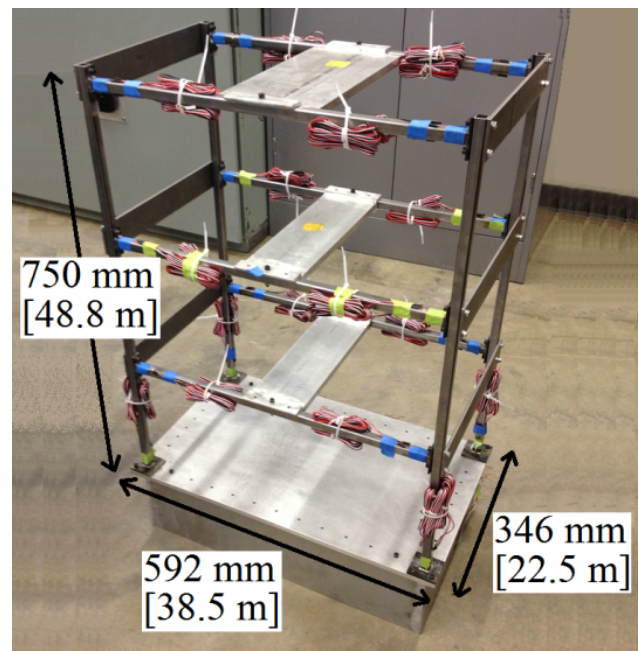

(a)

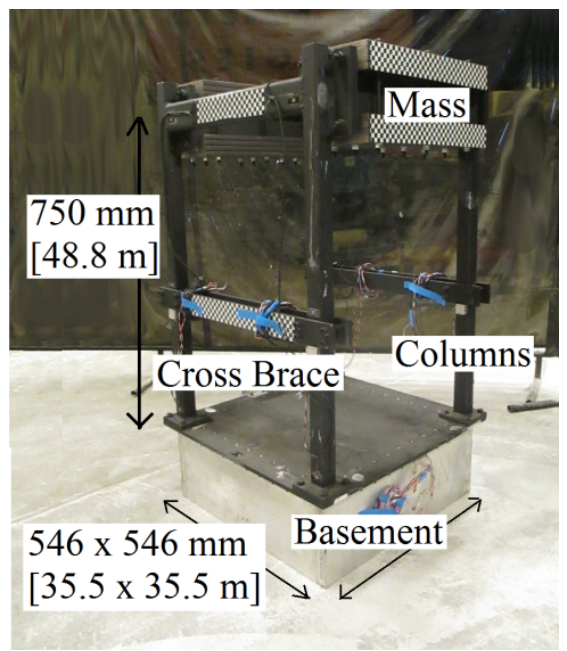

(b)

Figure 12. Photographs showing the finished: (a) midrise and; (b) highrise building models used in centrifuge. Dimensions shown in both model and [prototype scale]. 


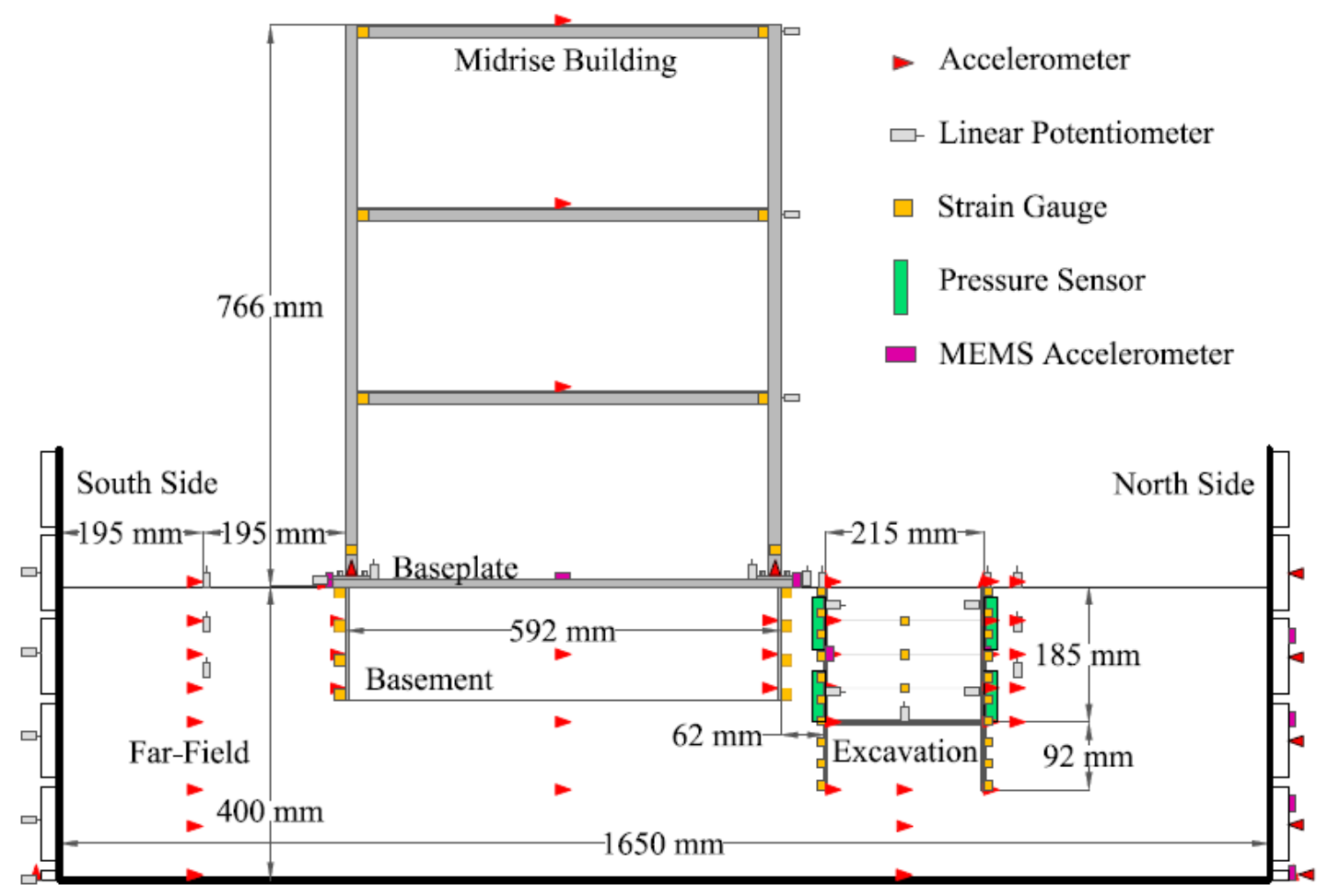

(a)

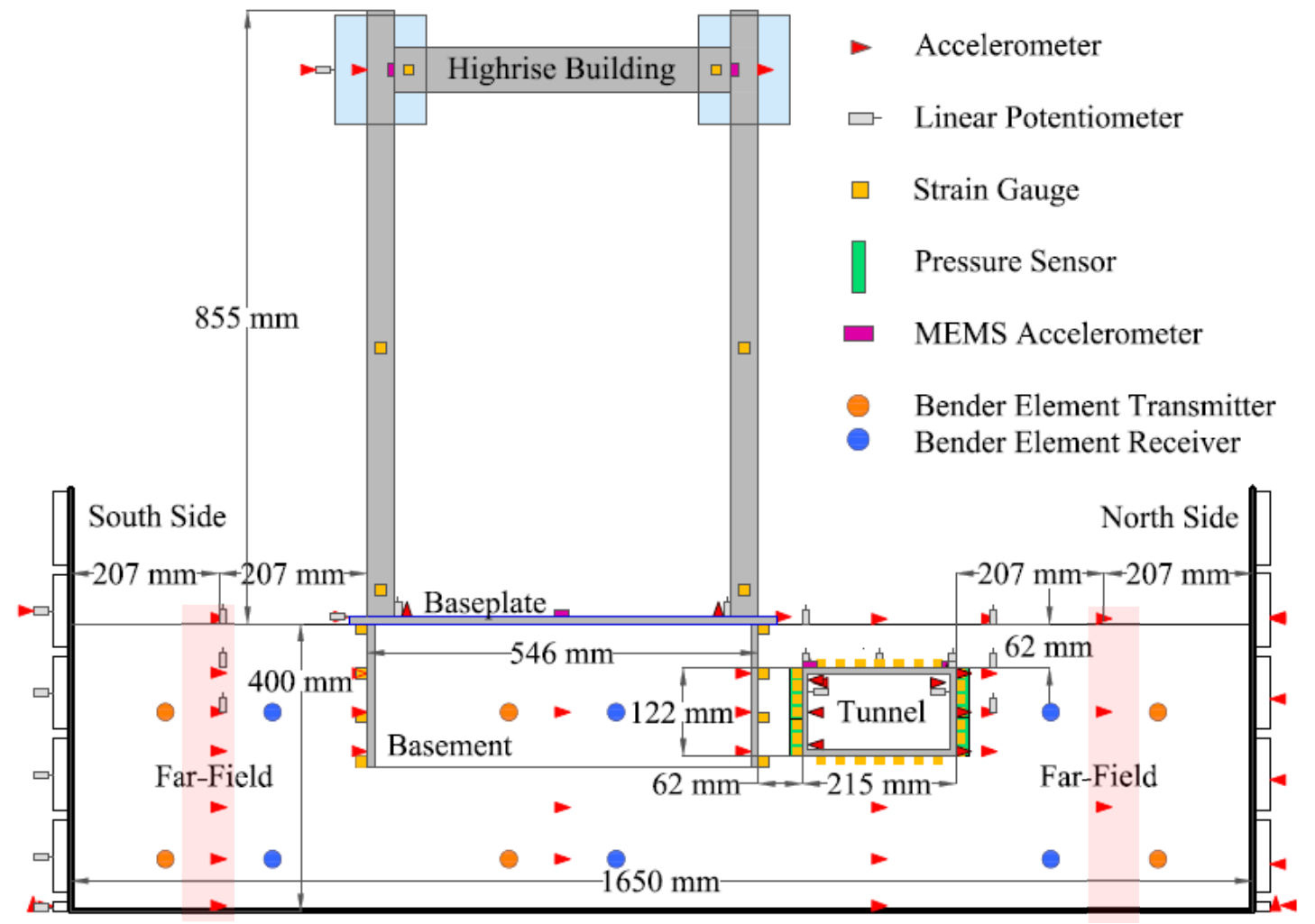

(b)

Figure 13. Elevation view of instrumentation layout in T-Midrise and T-Highrise (dimensions shown in model scale). 


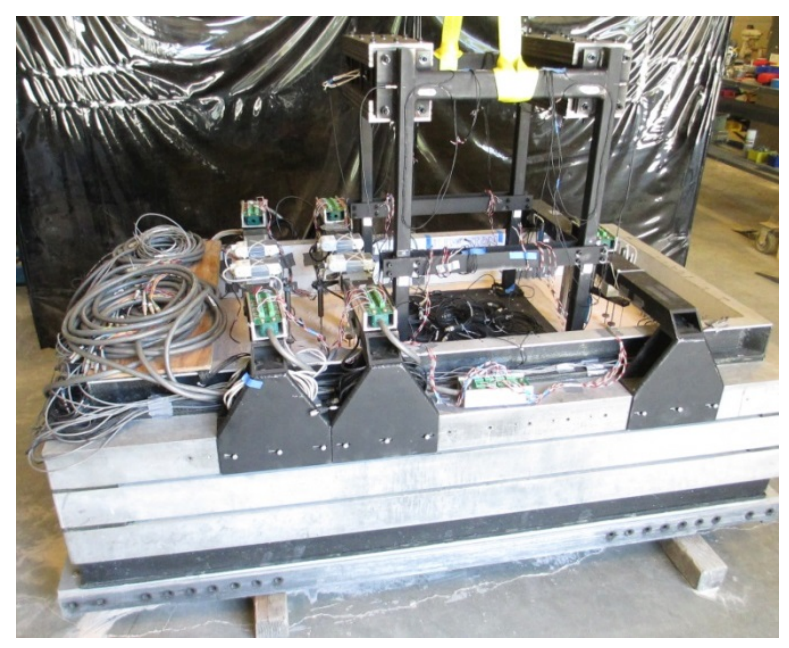

Figure 14. T-Highrise after model construction and instrumentation. 


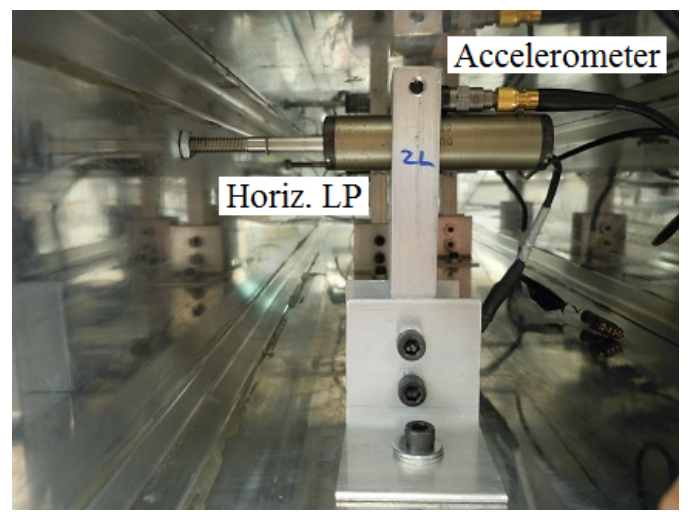

(a)

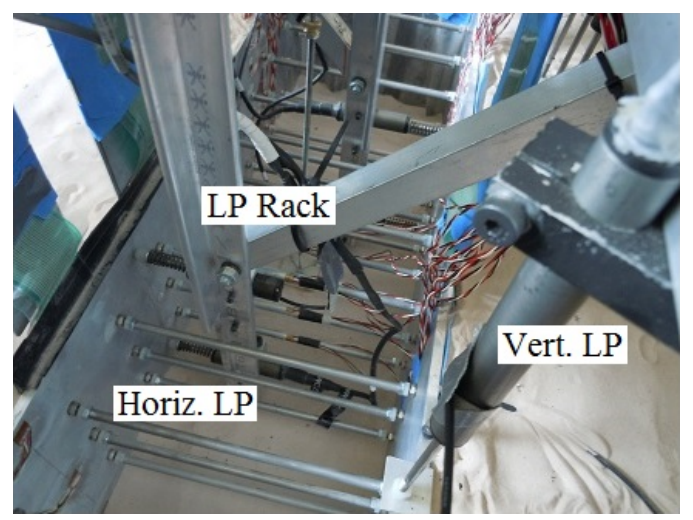

(b)

Figure 15. Measuring racking deformations directly with horizontally placed linear potentiometers (LPs) inside the: (a) permanent box structure; (b) temporary excavation. 


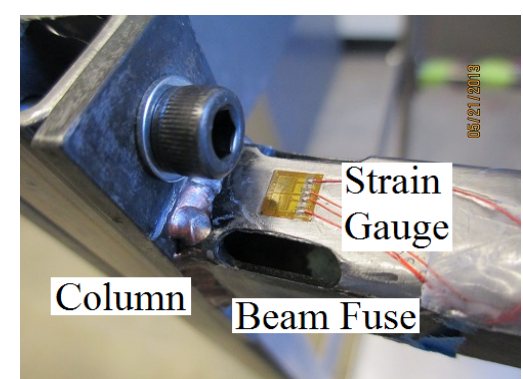

Figure 16. Midrise beam fuse and placement of a strain gauge in half bridge configuration. 

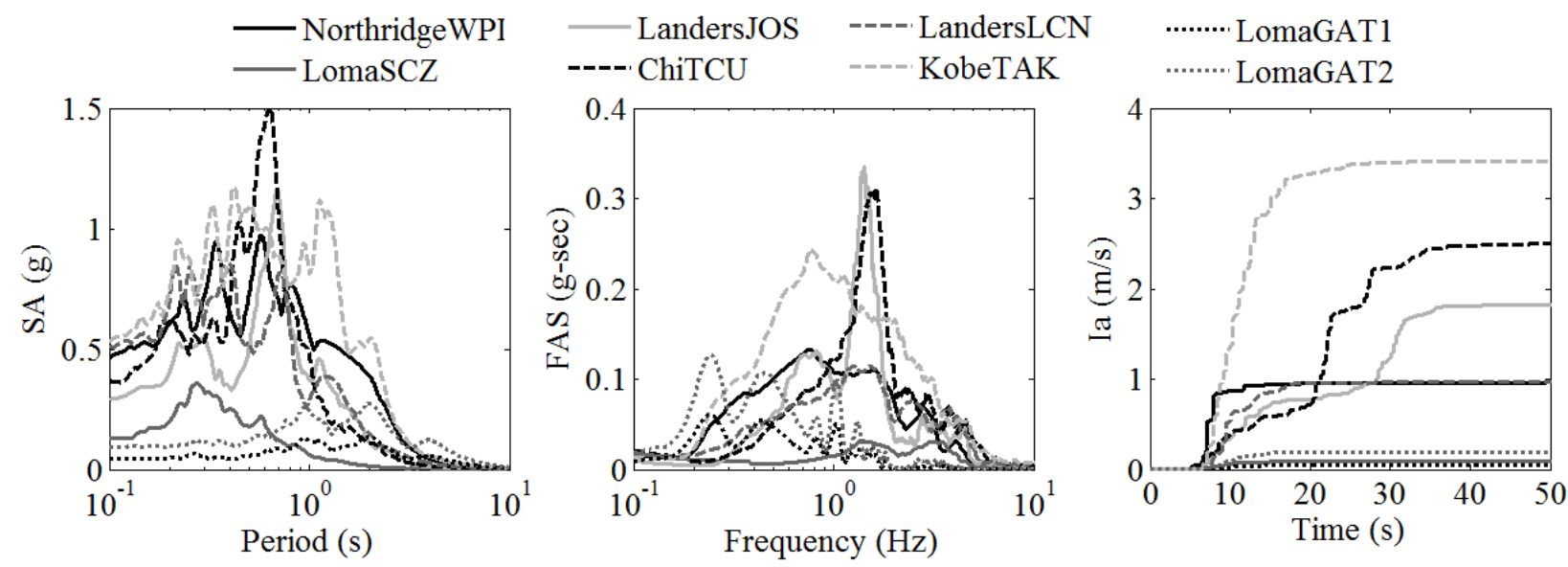

Figure 17. 5\%-damped acceleration response spectra, Fourier amplitude spectra, and Arias Intensity time histories of the achieved base motions in T-No Bldg (and in T-Highrise for LomaGAT motions). 


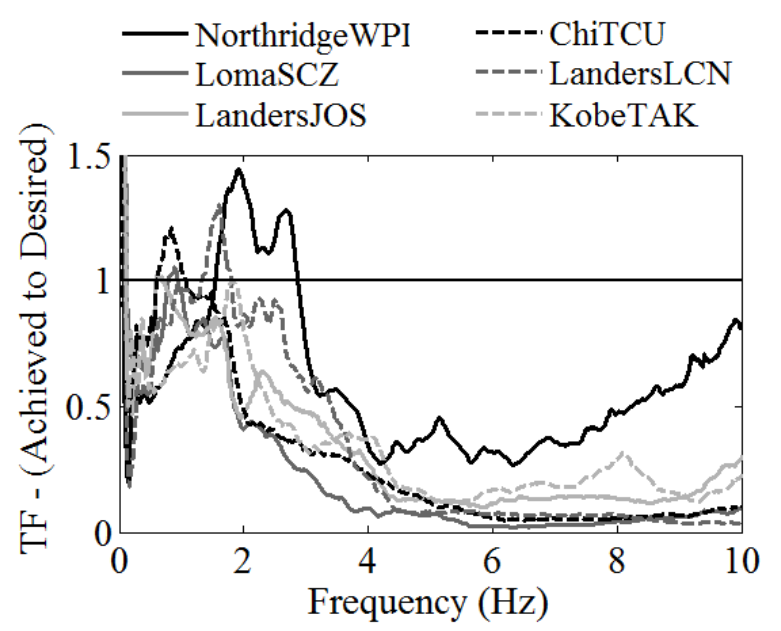

Figure 18. Transfer functions (TFs) of achieved to desired ground motions in T-No Bldg. 


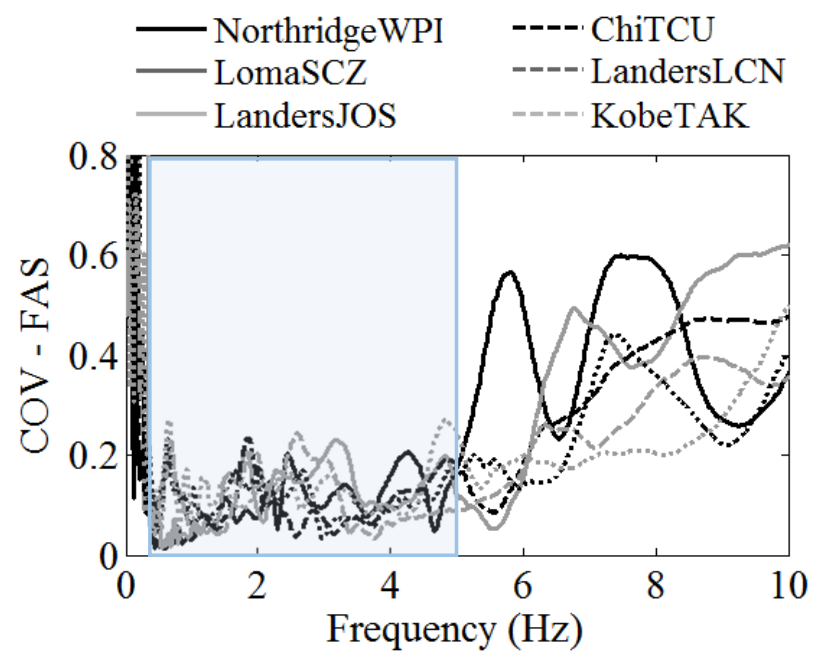

Figure 19. Coefficient of variation (CV) of each base motion recorded during six different centrifuge experiments. The highlighted area indicates the frequency range of interest: $0.1-5 \mathrm{~Hz}$. 